\title{
On Histochemical Studies of the Various Organs of Spontaneously Hypertensive Rats*
}

\author{
Ryo TABEI \\ Department of Pathology, Faculty of Medicine, Kyoto University, Kyoto
}

(Director : Prof. K. Okamoto)

$\mathrm{I}^{\mathrm{T}}$ IS GENERALLY accepted at present that hypertension is associated with many endocrine disorders in man and many experimental observations indicate that various endocrine glands are intimately related to blood pressure homeostasis.

In 1963, selective production of a strain of spontaneously hypertensive rats was reported by OKAмото and AokI ${ }^{1)}$. These rats are absolutely without parallel from the points of showing 100 per cent incidence of spontaneous occurrence of hypertension and a more severe hypertension than "inherited hypertension in rats" by Smirk et al. ${ }^{2-4)}$, and "spontaneously hypertensive rabbits" by ALEXANDER et al.5)6) Spontaneously hypertensive rats may be considered to be analogous to essential hypertensive humans, because of the absence of severe organ changes, especially in the cardiovascular-renal system before the development of hypertension ${ }^{7}$.

Окамото ${ }^{8)}$, Aoki et al. ${ }^{9)}$ and AokI ${ }^{10-12)}$ have studied primarily the endocrine organs of spontaneously hypertensive rats and have detected some slight but regular changes in them even from the pre-hypertensive stage and observed that these changes become more severe and intense according to age. Moreover, it has been demonstrated that removal of some of the endocrine organs in the pre-hypertensive stage prevents the development of hypertension $^{10)}$.

In the present study, the author histochemically examined various organs of spontaneously hypertensive rats, aiming at getting nearer to the functional aspects of these organs, and detected a few clear findings compared with normotensive control rats, some of which were presented from the pre-hypertensive stage. These will be considered from the standpoint of playing some significant roles in the development and maintenance of hypertension in this animal and further will be judged as a clue to elucidate the possible mechanism of human essential hypertension.

\section{Materials}

The Wistar strain rats of the control group consisted of rats supplied by the Animal Center Laboratory, Faculty of Medicine, Kyoto University and of the offsprings bred from these rats in the Department of Pathology under normal conditions. From among them only normotensive (below $149 \mathrm{~mm} \mathrm{Hg}$ ) rats were selected and used for the control (abbreviated as $\mathrm{N}$ hereafter). The hypertensive group consisted of $F_{7}$ to $F_{11}$ rats of spontaneously hypertensive rats (OKAmoto and AOKI)1)13) (abbreviated as SH henceforward). Although the method of selective production of spontaneously hypertensive rats, their body weight, blood pressure and incidence of hypertension have been already reported ${ }^{1 \text { ) 1.3) the }}$ method is briefly mentioned as follows :

Many weanling rats of the Wistar strain supplied by the Animal Center Laboratory, Faculty of Medicine, Kyoto University were kept in the Department of Pathology under normal conditions. From among these one male rat showing distinctly high blood pressure $(145-175 \mathrm{~mm} \mathrm{Hg})$ and a female rat with a blood pressure slightly above the average (130-140 $\mathrm{mm} \mathrm{Hg}$ ) were selected. After this male rat had persisted in high blood pressure of above $150 \mathrm{~mm} \mathrm{Hg}$ for over a month, the male rat was mated with the female rat to obtain $F_{1}$ rats. Many

(Received for Publication, April 19, 1966)

* An outline of this study was reported at the 54th Annual Meeting of the Japanese Pathological Society in April, 1965 and the 6th Annual Meeting of Japanese Histochemical and Cytochemical Association in Oct., 1965. This investigation was supported by a Grant-in-Aid for Scientific Research from the Japanese Ministry of Education. 
of these $F_{1}$ rats showed spontaneous hypertension. The process of mating these rats was repeated successively. In these rats, 100 per cent occurrence of spontaneous hypertension in $\mathrm{F}_{2}$ rats onward was observed within the first 5 months of life. By repeating this process, the generations have reached $\mathrm{F}_{12}$ at present.

A total of 90 rats was used in this study. All rats were sacrificed by decapitation after being divided into 3 groups according to survival duration : 40-60 days old (Stage I), 5-7 months (Stage II) and 13-17 months of age (Stage III). It the N group; rats in Stage I consisted of 16 male rats (case numbers, 252, 41, 48, 47, 42, 44, 43, 319, 321, 320, 45, $46,381,369,383,382)$, in Stage II, of 17 males $(66,68,69,242,246,227,245,316,261,14,21,313$, $311,312,323,338,17)$, and in Stage III, of 7 males $(103,133,57,64,54,58,60)$ and 5 females (121, $107,109,117,59)$. In the $\mathrm{SH}$ group ${ }^{13)}$; rats in Stage I consisted of 17 male rats (case numbers, 9078, T9027, T9054, T9053, 10095, 10096, 10013, 10053, 10059, 10055, 10056, 10057, T9123, T9124, $10241,10242,116001)$, in Stage II, of 16 males (T8022, T8011, 9057, 9058, 9055, 9064, 9065, T9011, 9074, 9075, 9077, T9032, 10030, 10063, T9086, 9099), and in Stage III, of 7 males (7046, $8001,8100,8102,8107,8109, \mathrm{~N} 9001)$ and 5 females (7084, 7056, 7053, 7082, N9004).

All animals were kept in an air-conditioned animal room with $25^{\circ} \mathrm{C} \pm 0.5^{\circ} \mathrm{C}$ of temperature and 50-60 per cent of humidity. These rats were fed on Oriental's stock chow diet (NMF and MF) (Oriental Yeast Co., Japan) or boiled Manitoba wheet mixed with cooked dried sardine, and seasoned with a little salt ( 0.3 per cent $\mathrm{Na})$ and sometimes green vegetables. Tap water was given ad libitum.

\section{Methods}

General Observations:- The blood pressure and body weight of all rats were measured once a week all through life beginning at 4 weeks of age. The systolic blood pressure was measured indirectly without anesthesia by the modified tail-water plethysmographic method (OKamoto and AokI)1).

ORGAN WEIGHT :- Immediately after decapitation, the adrenals, thyroid, kidneys, heart, liver and pancreas were taken out and removed of coagulated blood, adipose and connective tissues adhering to them. The adrenals and thyroid were weighed on a torsion balance. The kidneys, heart, liver and pancreas were weighed on a lever balance. The organ weight was indicated as the organ weight to body weight ratio:

$\begin{array}{ll}\frac{\text { organ weight }(\mathrm{gm})}{\text { body weight }(\mathrm{gm})} \times 10^{5} & \begin{array}{l}\text { for the adrenals and } \\ \text { thyroid }\end{array} \\ \frac{\text { organ weight }(\mathrm{gm})}{\text { body weight }(\mathrm{gm})} \times 10^{3} & \begin{array}{l}\text { for the kidneys, heart } \\ \text { liver and pancreas }\end{array}\end{array}$

Enzyme Histochemical Examination:- Six organs, i.e. adrenals, thyroid, kidneys, heart, liver and pancreas were examined. The left adrenal, one lobe of the thyroid, a slice from the mid portion of the kidney, a transverse section of the heart, a sagittal section of the liver and the tail part of the pancreas were mounted on blocks with a small quantity of water, soaked in liquid n-hexan and indirectly frozen by a mixture of crushed solid carbon dioxide and acetone through the medium. These frozen blocks were then stored in a deep freezer temporarily. Frozen sections were made in cryostats partly by a HARRIs cryostat (Model No. M 40, U.S.A.) and partly by a DitTes-Dusprva cryostat (Germany) maintained at $-20^{\circ} \mathrm{C}$ with a thickness of $15 \mu$ and were attached to cover slip glass by momentary thawing by the heat of fingers. These sections were stored again in the deep freezer.

Then twenty-one kinds of enzyme activity were examined on these six kinds of section from the $\mathrm{SH}$ group and corresponding control group at the same time. The kinds of enzymes examined histochemically and the staining method applied are given in Table I.

Each incubation period applied in the pressent study is illustrated in Table I. In these methods, the following 5 improvements were added : -

First, for the demonstration of ACPase activity, GomorI's metal-salt method ${ }^{17) 18}$ ) was modified to a slight extent, especially in preparation of the incubation medium, with due regard to the advice of

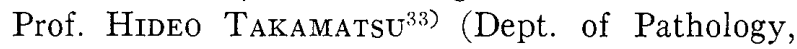
Tuberculosis Research Institute, Kyoto University, Kyoto) as follows : $13 \mathrm{ml}$ of 3 per cent sodium- $\beta$ glycerophosphate solution and $10 \mathrm{ml}$ of $0.25 \mathrm{M}$ acetate buffer at $\mathrm{pH} 4.6$ were mixed and added to distilled water to a total volume of $90 \mathrm{ml}$, followed by the addition of $10 \mathrm{ml}$ of 2 per cent lead nitrate solution drop by drop gently to form a coarse turbid product. The incubation medium was obtained by filtration of the mixture. Unfixed cryostat sections were incubated in an oven at $37^{\circ} \mathrm{C}$ for periods of 60 minutes. The slides were then washed thoroughly in distilled water and immersed in diluted yellow ammonium disulfide solution for about 3 minutes. After washing, post-fixation and washing again, the slides were mounted.

Second, adenosine triphosphate, the substrate for the ATPase was reduced by one-fourth the quantity used in the original method ${ }^{19)}$ and glucose-6-phosphate disodium salt, the substrate of the G-6-PD was reduced similarly by one-third ${ }^{29)}$, owing to the occurrence of too intense reactions.

Third, in the cases of ATPase ${ }^{19)}$, glucose-6phophatase $^{20)}, 5^{\prime}$-nucleotidase ${ }^{21)}$ and steroid-3 $\beta$-ol dehydrogenase ${ }^{30)}$, each substrate solution was filtered before incubation. 
Table I Histochemical Examination Methods of Various Enzymes

\begin{tabular}{|c|c|c|}
\hline \multicolumn{2}{|l|}{ Phosphatases } & $\begin{array}{l}\text { Incubation } \\
\text { Period } \\
\text { (minutes) }\end{array}$ \\
\hline 1. Alkaline Phosphatase (Naphthol AS Phosphate Method) & Burstone $e^{14-16)}$ & 60 \\
\hline 2. Acid Phosphatase (ACPase) (Metal-Salt (Pb) Method)* & Gomori $\left.\left.{ }^{17}\right) 18\right)$ & 60 \\
\hline 3. Adenosine Triphosphatase (ATPase) (Metal-Salt (Pb) Method)* & Wachstein and Meisel $\left.{ }^{19}\right)$ & 50 \\
\hline 4. Glucose-6-Phosphatase (Metal-Salt (Pb) Method)* & Wachstein and Meisel20) & 50 \\
\hline 5. 5'-Nucleotidase (Metal-Salt $(P b)$ Method)* & Wachstein and Meisel 21$)$ & 20 \\
\hline \multicolumn{3}{|l|}{ Esterases } \\
\hline 6. Esterase (Naphthol AS-D Acetate Method) & Burstone 22$) 23)$ & 180 \\
\hline 7. Lipase (Tween 80 Method)* & Gomori ${ }^{24)}$ & 240 \\
\hline \multirow{2}{*}{\multicolumn{3}{|c|}{$\begin{array}{l}\text { 8. Cholinesterase (Acetylthiocho } \\
\text { Oxidases }\end{array}$}} \\
\hline & & \\
\hline 9. Monoamine Oxidase (MAO) (Tetrazolium Method) & Glenner, Burtner and Brown ${ }^{25)}$ & 80 \\
\hline 10. Cytochrome Oxidase ( $N$-Phenyl-p-Phenylenediamine Method) & Burstone 26 & 60 \\
\hline \multicolumn{3}{|l|}{ Dehydrogenases (All by Tetrazolium Method) } \\
\hline 11. Diphosphopyridine Nucleotide Diaphorase & Burstone ${ }^{27)}$ & 15 \\
\hline 12. Triphosphopyridine Nucleotide Diaphorase (TPND) & Burstone ${ }^{27)}$ & 20 \\
\hline 13. Succinic Dehydrogenase & $\begin{array}{l}\text { Nachlas, Tsou, Souza, Chang and } \\
\quad \text { Seligman }{ }^{28)}\end{array}$ & 40 \\
\hline 14. Lactic Dehydrogenase* & Hess, Scarpelli and Pearse ${ }^{29)}$ & 20 \\
\hline 15. Glucose-6-Phosphate Dehydrogenase $(G-6-P D)^{*}$ & Hess, Scarpelli and Pearse ${ }^{29}$ ) & 30 \\
\hline 16. Steroid-3ß-ol-Dehydrogenase* & Levy, Deane and Rubin ${ }^{30)}$ & 60 \\
\hline 17. Glutamic Dehydrogenase & Hess, Scarpelli and Pearse $e^{2.9}$ & 60 \\
\hline 18. Ethanol Dehydrogenase & Hess, Scarpelli and Pearse ${ }^{29)}$ & 90 \\
\hline 19. Malic Dehydrogenase & Hess, Scarpelli and Pearse $\left.{ }^{29}\right)$ & 120 \\
\hline \multicolumn{3}{|l|}{ Glycosidase } \\
\hline 20. $\beta$-Glucuronidase (Post-Coupling Azo-Dye Method) & Seligman, Tsou, Rutenburg and Cohen ${ }^{31)}$ & 31) 180 \\
\hline \multicolumn{3}{|l|}{ Proteolytic Enzyme } \\
\hline 21. Leucine Aminopeptidase (Azo-Dye Method) & Nachlas, Crawford and Seligman 32$)$ & 120 \\
\hline
\end{tabular}

Fourth, in determination of lipase activity ${ }^{24)}$, sodium cholate, as an activator, was added to the incubation medium by 0.005 per cent in final concentration $^{34) 35)}$.

Fifth, the substrate of lactic dehydrogenase ${ }^{29)}$, stock 0.5 M sodium lactate itself is fairly high in $\mathrm{pH}$ value, so that it was lowered to approximately $\mathrm{pH} 7.4$ by the addition of $1 \mathrm{~N}$ hydrochloride solution in advance.

Before incubation the slides were brought to room temperature and dried by air. For staining, each kind of unfixed cryostat section was incubated in each medium. After staining, these sections were post-fixed in 8 per cent neutral formalin for over 30 minutes, after mounting in Apáthy gummy syrup. Throughout this enzyme histochemical process, from sacrifice to slide mounting, materials from the hypertensives and those controls were examined simultaneously and the slides were mounted in pairs on the same slide glass. On the other hand, each technical control section was employed, omitting substrate from the media.
Findings were obtained by comparing the section of hypertensive to that of control, mounted on the same slide, with a light microscope. On that occasion, the reaction observed in the technical control section was not regarded as a nonspecific product.

Histochemicai and Histometrical Examination for the Adrenal Medulla:- -

a) Noradrenalin Reaction using the GlutaraldehydeOsmium Tetroxide Technique ${ }^{36}$ ). The right adrenals were removed both from the normotensives and the hypertensives and sliced sagittally including the mid-plane of the medulla about $3 \mathrm{~mm}$ thick. After being fixed by immersion in cold $\left(0^{\circ}-4^{\circ} \mathrm{C}\right) 6$ per cent glutaraldehyde buffered to $\mathrm{pH} 7.3$ with $0.1 \mathrm{M}$ phosphate for a period of more than 2 hours, these adrenal slices were cut on the termo-electro freezing microtome (Komatsu Electronics Inc., Japan) at $15 \mu$ and the sections afterwards transferred to 1 per cent cold veronal acetate-buffered osmium tetroxide $(\mathrm{pH}$ 7.3) for a period of about 70 minutes. They were then washed in distilled water and afterwards mounted in Apáthy gummy syrup. 
b) Histometrical Examination. The areas of the medulla in cross-sections stained with this technique were projected with an ERNST LEITz microprojector (Type VX501 $1_{r}$-3b with xenon lamp, Germany) at about 310 magnification on sheets of section paper to measure the whole cross-sectional area and the area of noradrenalin-storing cell islets with a planimeter.

Three sections containing the medulla were chosen at random from every adrenal and similarily measured. For each section the dimensional ratio of noradrenalin-storing cell islets to the whole adrenal medulla was calculated as follows :

area of noradrenalin-storing cell islets

area of whole adrenal medulla $\times 100(\%)$

These three values were averaged for each rat. The mean values were measured for each animal group in Stages I, II and III of both $\mathrm{N}$ and SH groups, each of which consisted of five cases. Afterwards, the relationship of the dimensional ratio of the $\mathrm{SH}$ group to that of the $\mathrm{N}$ group was calculated for each stage :

dimensional ratio of the $\mathrm{SH}$ group dimensional ratio of the $\mathrm{N}$ group

Statistical Analysis:- The data thus obtained from the normotensive and hypertensive groups were statistically analyzed using " $t$ " test, and the data were considered significant when the " $p$ " values were less than 0.01 .

\section{Results}

All the finding of the $\mathrm{SH}$ group were compared with those from the $\mathrm{N}$ group of the same sex and with almost the same survival duration.

Body WeIGHT:- There was no significant difference between the $\mathrm{N}$ and $\mathrm{SH}$ groups (Tables II, IV, VI, VIII, X, XII) within each stage and within each histochemical group.

Blood Pressure:- The mean systolic blood pressure of the $\mathrm{N}$ group remained in the range of from 110 to $126 \mathrm{~mm} \mathrm{Hg}$. In the $\mathrm{SH}$ group, it rose steadily with age and was significantly higher than that of the $\mathrm{N}$ group. There exist significant differences between the $\mathrm{N}$ and $\mathrm{SH}$ groups in mean systolic blood pressure as follows: G-6-PD group ; in Stages I and II and males in Stage III, TPND group; in all stages, noradrenalin reaction group; in all stages, ACPase group ; in Stages II and III, ATPase group ; Stages I and II and males in Stage III, MAO group; in all stages.

ORgAN WeIgHt:- The ratios of organ weight to body weight of rats in both the $\mathrm{N}$ and $\mathrm{SH}$ groups used in this study are shown in Tables II, IV, VI, VIII, X and XII.

Adrenals:- There was no significant difference among histochemical groups using adrenals in all stages.

Thyroid : - The thyroids of males of the $\mathrm{SH}$ group in Stage III were significantly heavier in weight than those of the $\mathrm{N}$ group but there was no significant difference in Stages I and II.

Kidneys :- The weight of kidneys of the $\mathrm{SH}$ group for the investigation of ATPase activity was significantly higher in Stage II but there was no significant difference in Stage I or in either sex of Stage III.

Heart:- In the SH group, the weight of the heart was significantly greater in Stage II and in males in Stage III than in the $\mathrm{N}$ group, but there was no significant difference in Stage I or in females in Stage III.

As to the age of the animals, the organ-body weight ratio of the adrenals (in G-6-PD, TPND, and noradrenalin reaction groups) was largest in Stage I, and was larger in Stage II than in males in Stage III both in the $\mathrm{N}$ and $\mathrm{SH}$ groups. In Stage III, females of the N group showed a ratio larger than males of the $\mathrm{N}$ group but smaller than in Stage I. Though the females in Stage III consisted of only a few cases, they seemed to show the same tendency as the males in Stage III concerning the adrenals. As to the thyroid, no difference was found between any stages of the $\mathrm{N}$ and $\mathrm{SH}$ groups. The kidneys, in both $\mathrm{N}$ and $\mathrm{SH}$ group rats in Stage I showed greater value relative to body weight than those in Stages II and III but no difference between Stages II and III respectively. The heart-body weight ratio was slightly greater in rats of the $\mathrm{N}$ group in Stage I than in Stages II or III but there was no difference between Stages II and III. In Stages II and III the SH group showed significantly greater heart-body weight ratios than the $\mathrm{N}$ group, and the $\mathrm{SH}$ group revealed an almost unchanging ratio value through Stages I, II and III.

Besides the organs mentioned above, the liver and pancreas showed no remarkable change in the organ-body weight ratio. 


\begin{tabular}{|c|c|c|c|c|c|}
\hline 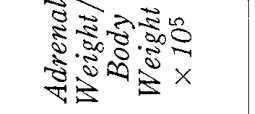 & 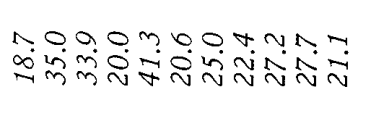 & 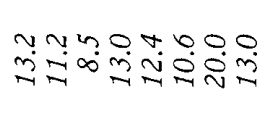 & 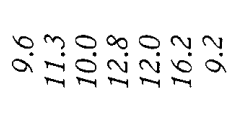 & 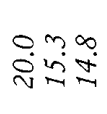 & \\
\hline 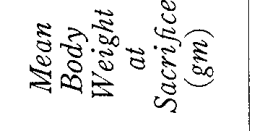 & 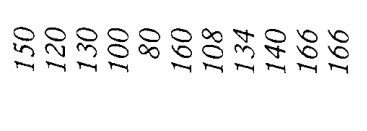 & 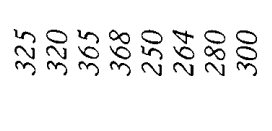 & 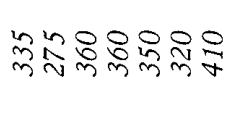 & 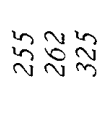 & \\
\hline 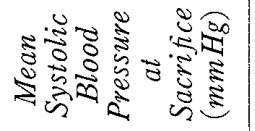 & 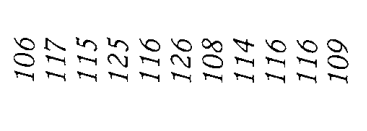 & 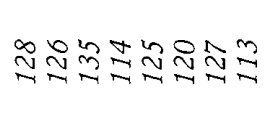 & 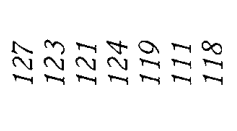 & 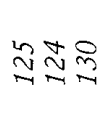 & \\
\hline 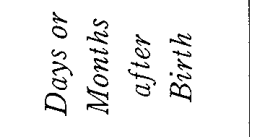 & 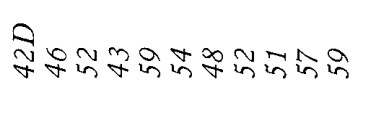 & $\mathbb{Z}_{010}$ on & 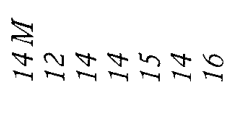 & $\pm \pi$ & \\
\hline 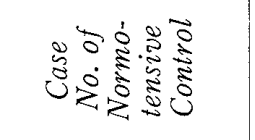 & 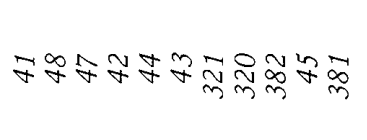 & 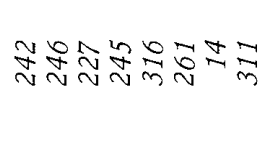 & 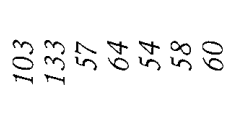 & 은욫ㄱ & 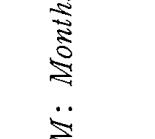 \\
\hline 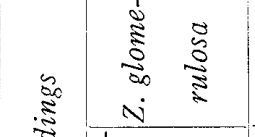 & $\hat{i} \uparrow \hat{i} \uparrow \hat{\imath} \uparrow \uparrow \hat{\imath} \uparrow \uparrow \uparrow$ & $\leftrightarrows \leftarrow \leftarrow \leftarrow \uparrow \leftarrow \ll \leftarrow$ & $\hat{\imath} \leftarrow \leftarrow \leftarrow \leftarrow \leftarrow \leftarrow$ & $\leftarrow \leftarrow \leftarrow$ & $\sum_{0}^{\infty} \frac{\dot{d}}{8}$ \\
\hline 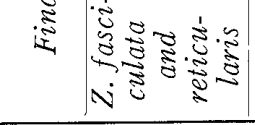 & $\leftarrow \leftarrow \leftarrow \leftarrow \leftarrow \leftarrow \leftarrow \leftarrow \leftarrow \leftarrow \leftarrow$ & $\leftleftarrows \longleftarrow \leftarrow \leftarrow \nleftarrow \leftarrow \leftarrow \leftleftarrows$ & $\leftrightarrow \longleftarrow \leftarrow \leftarrow \leftarrow \leftarrow \leftarrow$ & $\leftleftarrows \leftarrow \leftarrow$ & 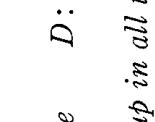 \\
\hline 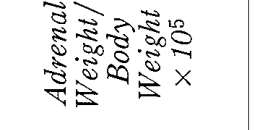 & 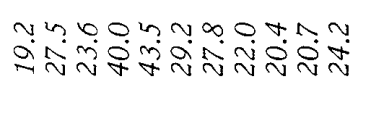 & 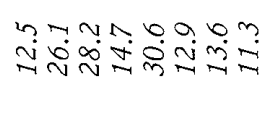 & 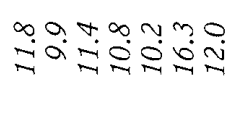 & 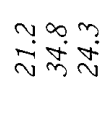 & 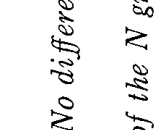 \\
\hline 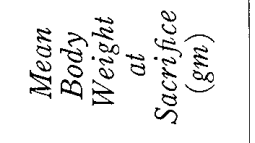 & 곡웡 & 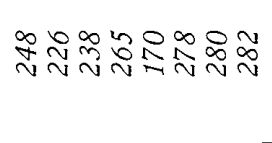 & 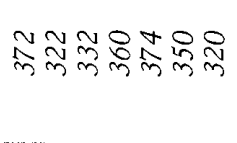 & $8 \stackrel{2}{2} \stackrel{n}{\sim}$ & 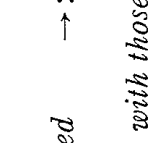 \\
\hline 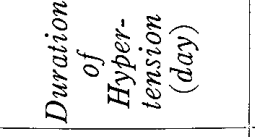 & 00000000000 & aฟ & 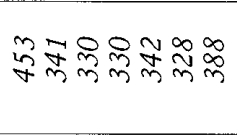 & $\underset{\sigma}{\sigma} \bar{\sigma} \hat{\sigma}$ & 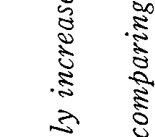 \\
\hline 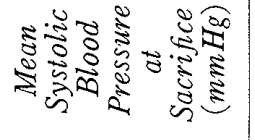 & 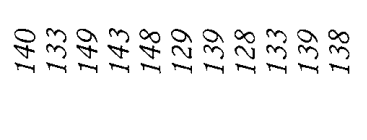 & 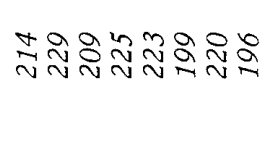 & 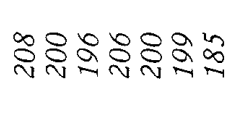 & จํำ & 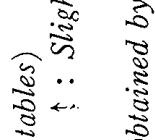 \\
\hline 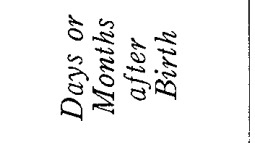 & 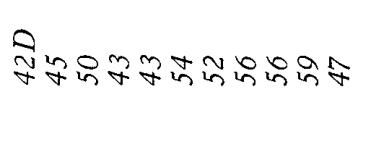 & Sobobinbon & 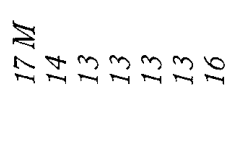 & 워소 & 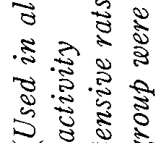 \\
\hline$\sum_{i}^{\circ} \quad \underset{n}{2}$ & 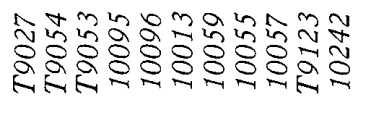 & 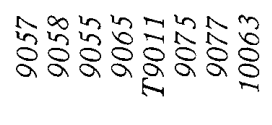 & 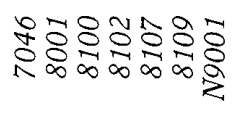 & 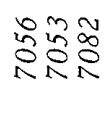 & 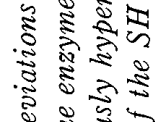 \\
\hline$\tilde{y}^{5}$ & $-\sim m+n$ 에 $\infty$ a은 & $\because v m+\ln 6 \wedge \infty$ & $\forall N m+n b N$ & $\infty \circ ?$ & 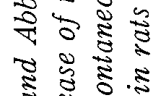 \\
\hline 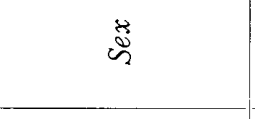 & to & $\leftarrow 0$ & to & ot & 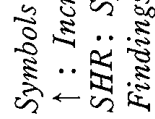 \\
\hline 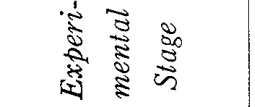 & - & $\Xi$ & $\Xi$ & & \\
\hline
\end{tabular}




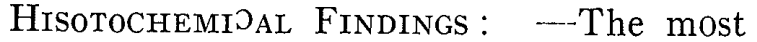
positive findings were found in rats of the $\mathrm{SH}$ group compared with each of the same sex rats fo the $\mathrm{N}$ group with almost the same survival duration. The increase of the enzyme activity was scored as follows:

$\uparrow:$ slightly increased

$\uparrow:$ moderately increased

$\uparrow \uparrow:$ markedly increased

$\uparrow \uparrow \uparrow:$ most markedly increased

$\downarrow$ : slightly decreased

$\downarrow$ : moderately decreased

1) G-6-PD Activity in the Adrenal Cortex. (Table II, Figs. 1-4). The G-6-PD reaction was observed in the adrenal cortex of the $\mathrm{N}$ group in all stages. Extensive reaction was detected in cells of the zona fasciculata and reticularis with the greatest concentration present in the middle and outer part of the fasciculata. The glomerulosa showed considerably less activity.

Zona fasciculata and reticularis: Moderate increase of G-6-PD activity in the adrenal cortex, especially in the middle and outer part of its zona fasciculata, of the $\mathrm{SH}$ rats was detected from Stage I and a more prominent increasing tendency of this activity was observed after Stage II, most remarkably in Stage III (Figs. 1-4). In Stage II, among a total of 8 cases which showed increase of the activity, 3 cases increased markedly. In Stage III, both males and females showed elevation and in a total of 10, 7 showed a marked increase of the activity.

Zona glomerulosa : No increase was observed in Stage I (Figs. 1, 2). In Stage II, increase was observed in all cases except one, and among them 2 cases increased markedly (Figs. $3,4)$. SH rats in Stage III, all but one showed a moderate increase. Although the activity increased in the glomerulosa, it was not as extensive as in the fasciculata and reticularis in both the $\mathrm{N}$ and $\mathrm{SH}$ groups.

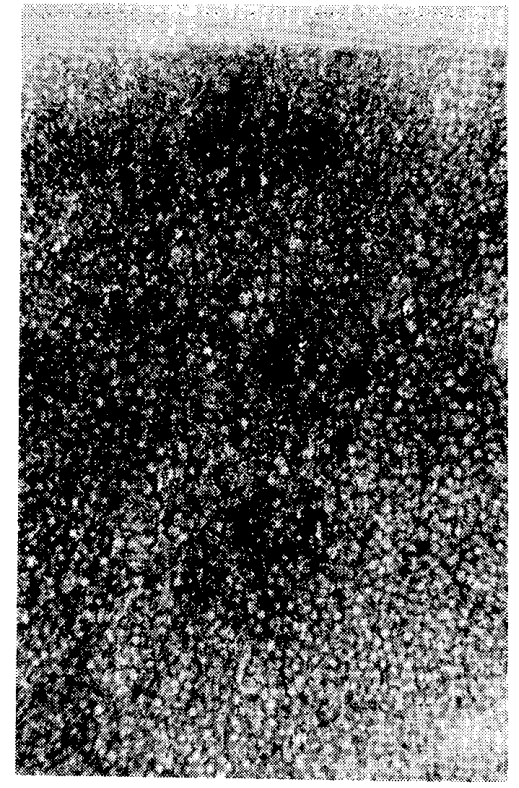

Fig. 1. G-6-PD activity in the adrenal cortex of a normotensive rat (No. 42, male, 43 days old). (By tetrazolium method). ( $\times 100)$. The reaction is mainly observed in the zona fascicutata and reticularis. The glomerulosa shows considerable less activity.

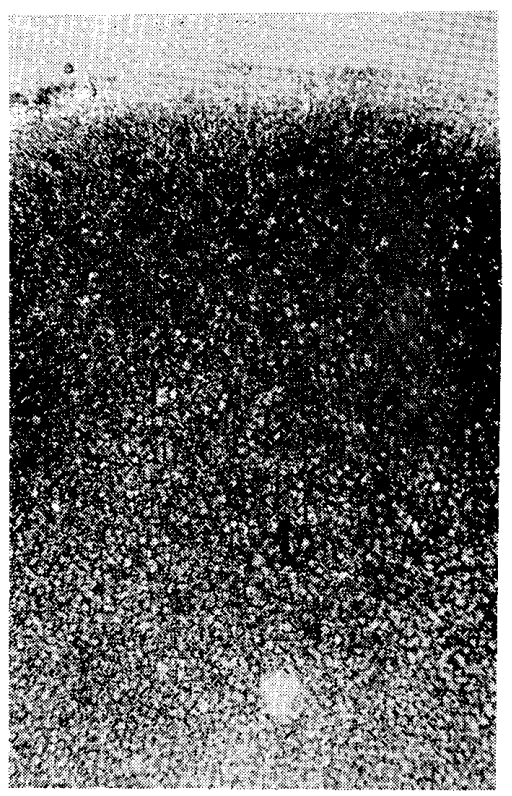

Fig. 2. G-6-PD activity in the adrenal cortex of a SH rat (No. 10095, male, 43 days old, prehypertensive stage). (By tetrazolium method). $(\times 100)$. The activity shows moderate increase, especially in the middle and outer part of its fascicular zone compared to the control (Fig. 1). No increase is observed in the zona glomernlosa 


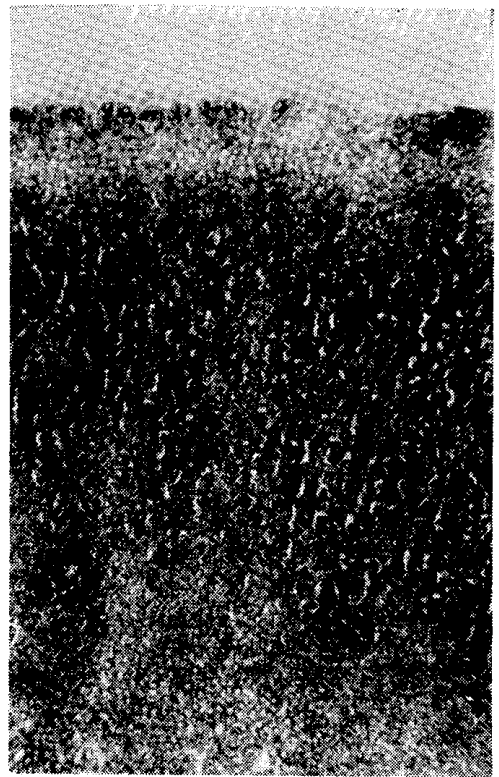

Fig. 3. G-6-PD activity in the adrenal cortex of a normotensive rat (No. 242, male, 6 months of age). (By tetrazolium method). $(\times 100)$. The reaction is observed intensely in the zona fasciculata and reticularis. The glomerulosa also shows moderate activity.

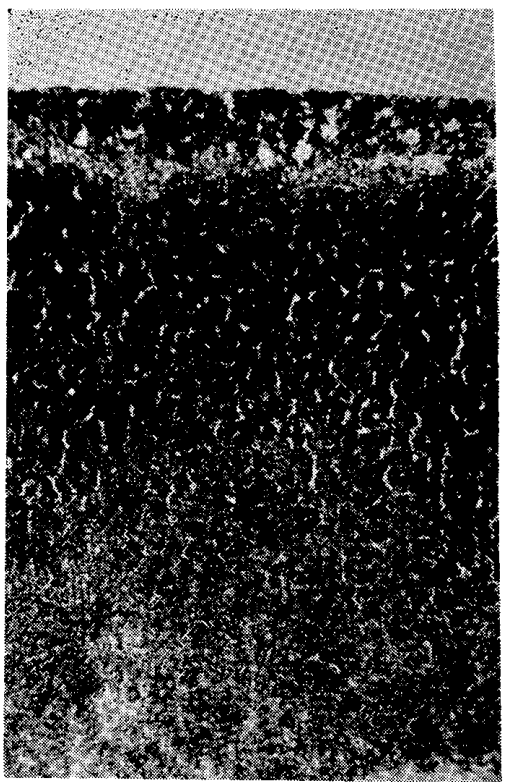

Fig. 4. G-6-PD activity in the adrenal cortex of a SH rat (No. 9057, male, 6 months of age, initial stage of hypertension). (By tetrazolium method). ( $\times 100)$. More prominent increase of the activity is observed in the zona fasciculata and reticularis. The activity is enhanced also in the zona glomerulosa.

Table III Total Average Values of G-6-PD Activity in the Adrenal Cortex

\begin{tabular}{|c|c|c|c|c|c|c|c|c|c|c|}
\hline \multirow{3}{*}{\multicolumn{2}{|c|}{$\begin{array}{l}\text { Experi- } \\
\text { mental } \\
\text { Stage }\end{array}$}} & \multirow{3}{*}{ Sex } & & \multirow{3}{*}{$\begin{array}{c}\text { No. of } \\
\text { Animals }\end{array}$} & \multirow{2}{*}{$\begin{array}{c}\text { Mean Systolic } \\
\text { Blood } \\
\text { Pressure } \\
\text { at Sacrifice } \\
(\mathrm{mm} \mathrm{Hg})\end{array}$} & \multirow{3}{*}{$\begin{array}{l}\text { Duration } \\
\text { of } \\
\text { Hyper- } \\
\text { tension } \\
\text { (day) }\end{array}$} & \multirow{2}{*}{$\begin{array}{l}\text { Mean Body } \\
\text { Weight at } \\
\text { Sacrifice } \\
\quad(\mathrm{gm})\end{array}$} & \multirow{3}{*}{$\begin{array}{c}\text { Adrenals } \\
\text { Weight/ } \\
\text { Body } \\
\text { Weight } \\
\frac{g m}{g m} \times 10^{5}\end{array}$} & \multicolumn{2}{|c|}{ Findings } \\
\hline & & & & & & & & & \multirow{2}{*}{$\begin{array}{c}\text { Z. fasci- } \\
\text { culata } \\
\text { and } \\
\text { reticula- } \\
\text { ris }\end{array}$} & \multirow{2}{*}{$\begin{array}{l}\text { Z. glome- } \\
\text { rulosa }\end{array}$} \\
\hline & & & & & mean S.D. & & mean (range) & & & \\
\hline \multirow[t]{2}{*}{$I$} & \multirow{2}{*}{$\begin{array}{l}42-59 \\
\text { Days } \\
\text { Old }\end{array}$} & \multirow[t]{2}{*}{$\hat{\delta}$} & $\begin{array}{c}\text { Normotensive } \\
\text { Control }\end{array}$ & 11 & $115 \pm 6.3$ & 0 & $132(80-166)$ & $26.6 \pm 7.3$ & & \multirow{2}{*}{$\longrightarrow$} \\
\hline & & & SHR & 11 & $138 \pm 7.0^{* * *}$ & 0 & $122(80-164)$ & $27.1 \pm 8.0$ & & \\
\hline \multirow[t]{2}{*}{$I I$} & \multirow{2}{*}{$\begin{array}{c}5-7 \\
\text { Months } \\
\text { of Age }\end{array}$} & \multirow[t]{2}{*}{3} & $\begin{array}{c}\text { Normotensive } \\
\text { Control }\end{array}$ & 8 & $124 \pm 7.4$ & 0 & $309(250-368)$ & $12.8 \pm 4.0$ & & \multirow{2}{*}{ 个 } \\
\hline & & & $S H R$ & 8 & $214 \pm 12.2 * *$ & $61-124$ & $248(170-282)$ & $18.7 \pm 8.0$ & & \\
\hline \multirow{4}{*}{$I I I$} & \multirow{4}{*}{$\begin{array}{l}13-17 \\
\text { Months } \\
\text { of Age }\end{array}$} & \multirow{2}{*}{$\delta$} & $\begin{array}{c}\text { Normotensive } \\
\text { Control }\end{array}$ & 7 & $120 \pm 5.2$ & 0 & $344(275-410)$ & $11.6 \pm 2.3$ & \multirow{2}{*}{$\uparrow \uparrow$} & \multirow{2}{*}{$\uparrow$} \\
\hline & & & $S H R$ & 7 & $199 \pm 7.5 * *$ & $328-453$ & $347(320-374)$ & $11.8 \pm 2.2$ & & \\
\hline & & \multirow[t]{2}{*}{ 우 } & $\begin{array}{c}\text { Normotensive } \\
\text { Control }\end{array}$ & 3 & $126 \pm 3.2$ & 0 & $281(255-325)$ & $16.7 \pm 2.9$ & \multirow{2}{*}{$\uparrow \uparrow$} & \multirow[t]{2}{*}{$\uparrow$} \\
\hline & & & $S H R$ & 3 & $196 \pm 34.2^{+}$ & $412-461$ & $249(233-260)$ & $26.7 \pm 7.1$ & & \\
\hline
\end{tabular}

S.D.: Standard deviation of the mean

$+0.01<p<0.05$

$* 0.001<p<0.01$

$* * p<0.001$

$\uparrow:$ About half the strength shown by $\uparrow$

Japanese Circulation Journal Vol. 3o, June 1966 


\begin{tabular}{|c|c|c|c|}
\hline 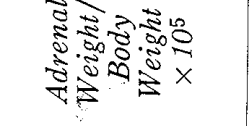 & 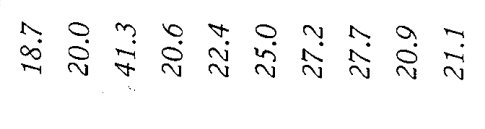 & 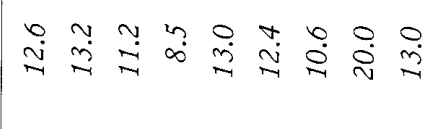 & 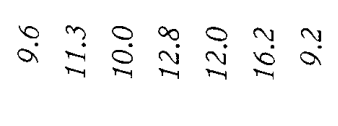 \\
\hline 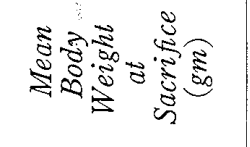 & 육유육 & 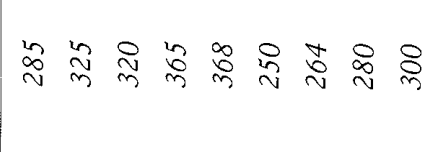 & 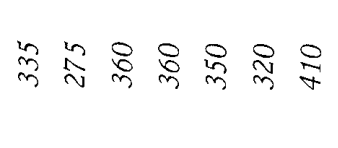 \\
\hline 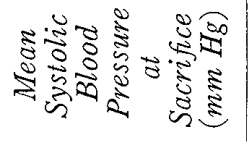 & 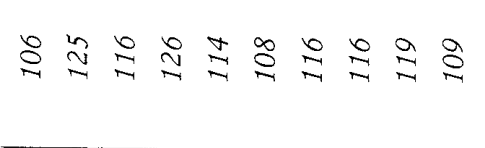 & 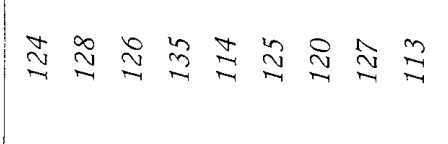 & 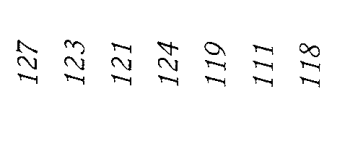 \\
\hline 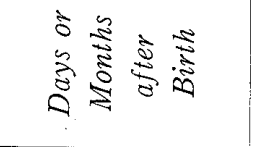 & 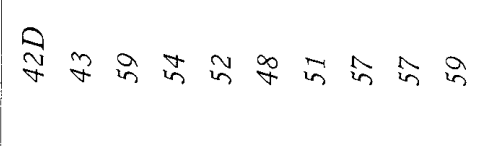 & İ ob 0 in o in in & 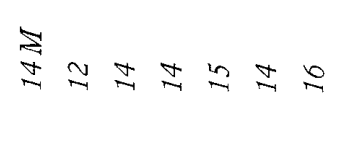 \\
\hline 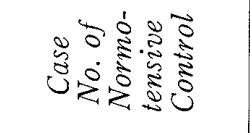 & 죽효 & 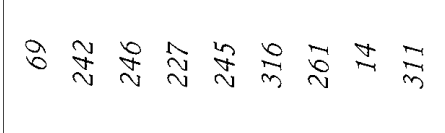 & 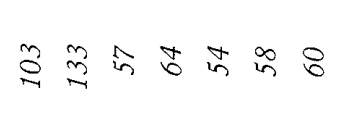 \\
\hline 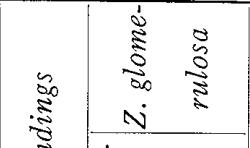 & 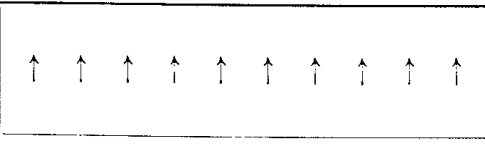 & $\leftarrow \leftarrow \leftarrow \leftarrow \leftarrow \uparrow \uparrow \uparrow \uparrow \uparrow$ & $\hat{\imath} \leftarrow \hat{\imath} \hat{\imath} \leftarrow \hat{\imath} \leftarrow$ \\
\hline 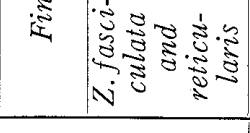 & $\leftarrow \leftarrow+\cdots \uparrow \ldots \leftarrow \leftleftarrows \leftarrow \uparrow$ & $\leftarrow \leftarrow \leftarrow \leftarrow \leftarrow \leftarrow \leftarrow \leftarrow \leftarrow$ & $\leftarrow \leftarrow \leftarrow \leftarrow+\leftarrow \leftarrow$ \\
\hline 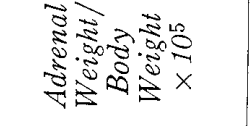 & 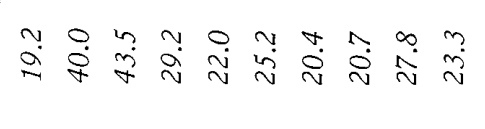 & 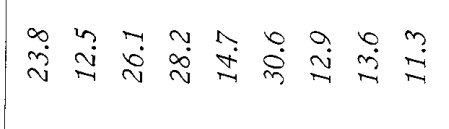 & 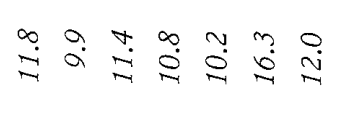 \\
\hline 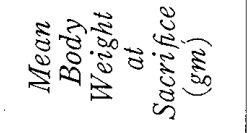 & 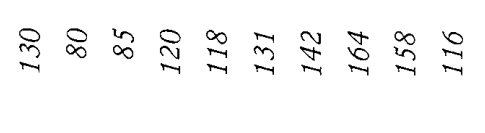 & 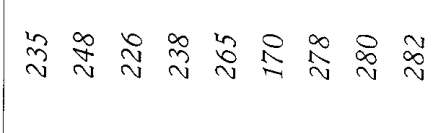 & 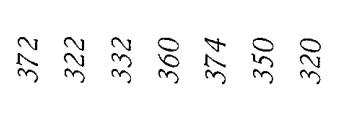 \\
\hline 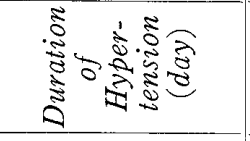 & 0000000000 & 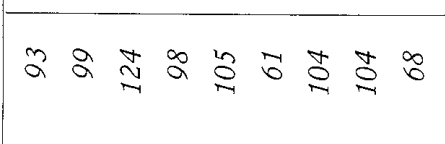 & 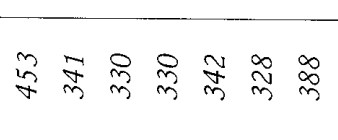 \\
\hline 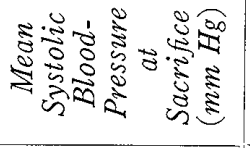 & 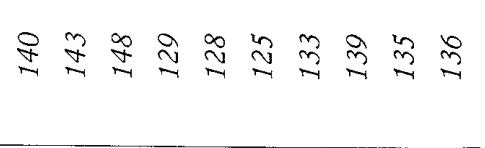 & 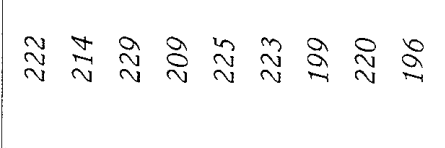 & 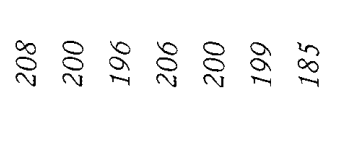 \\
\hline 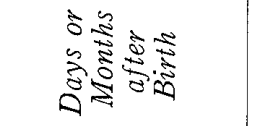 & 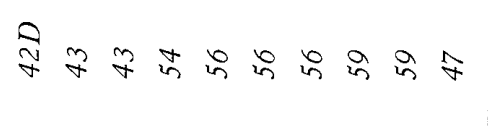 & $\mathbb{I} 0000 \mathrm{in} 0 \mathrm{~b}$ & 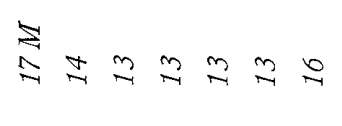 \\
\hline 造 & 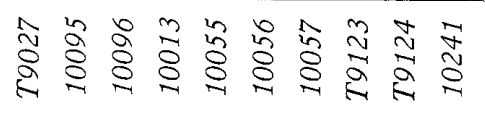 & 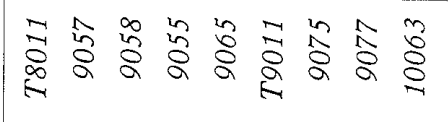 & 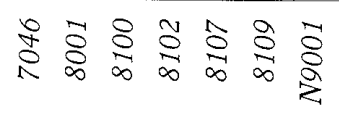 \\
\hline & $\pi \sim m+n b N \infty a ?$ & $\forall \sim m a n b \wedge \infty a$ & $r v m \forall n b N$ \\
\hline 离 & 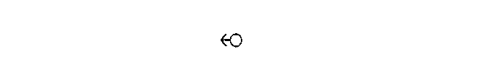 & + & to \\
\hline 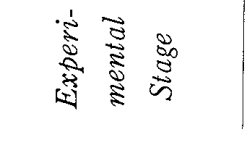 & - & $\succsim$ & $\lesssim$ \\
\hline
\end{tabular}




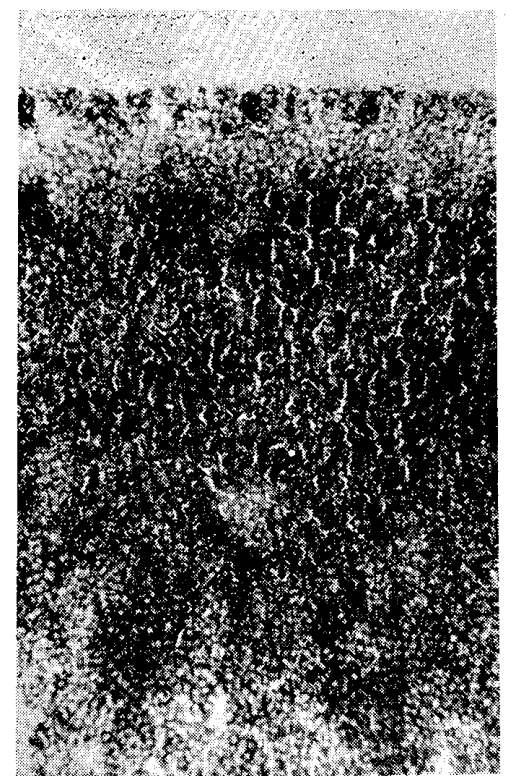

Fig. 5. TPND activity in the adrenal cortex of a normotensive rat (No. 246, male, 6 months of age). (By tetrazolium method). ( $\times 100)$. The reaction is observed in the fasciculata and reticularis, and slightly less in the glomerulosa.

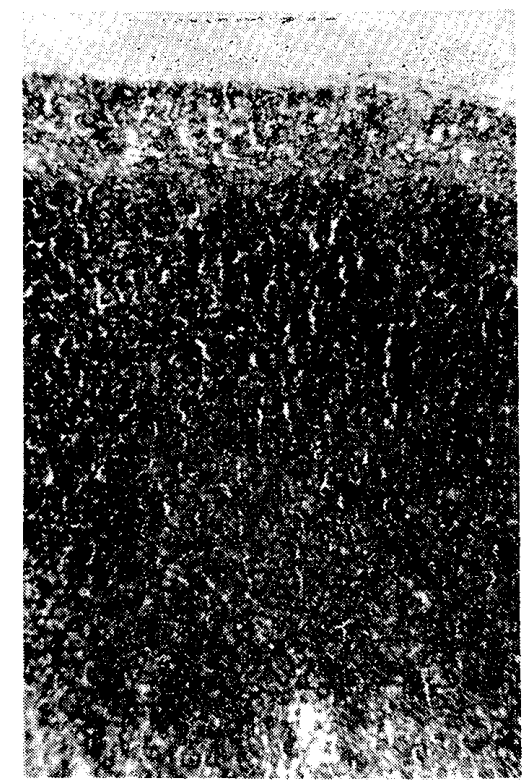

Fig. 6. TPND activity in the adrenal cortex of a SH rat (No. 9058, male, 6 months of age, initial stage of hypertension). (By tetrazolium method). ( $\times 100)$. Moderate enhancement of the activity is observed in the zona fasciculata and reticularis compared to the control (Fig. 5). An increasing tendency of the activity is also observed in the zona glomerulosa.
The findings of the G-6-PD activity detected in the adrenal cortex are summarized in Table III.

2) TPND Activity in the Adrenal Cortex. (Table IV, Figs. 5, 6). In the adrenal cortex of the $\mathrm{N}$ group, intense TPND activity was observed in the fasciculata and reticularis in all stages, but in sharp contrast to the case of the G-6-PD, these sections also showed comparatively intense enzyme activity in the glomerulosa. The increase of the activity in the glomerulosa, however, did not exceed that observed in the fasciculata and reticularis in any of the $\mathrm{N}$ group.

Zona fasciculata and reticularis: Increasing tendency of the activity in the SH group was observed from Stage I. Out of 10 rats, the increase was detected in 8 cases, one of which showed markedly, 4 of which showed slightly. In Stage II and in males in Stage III, moderate enhancement was observed in all of 9 and 7 cases, respectively (Figs. 5, 6). Although the TPND activity in the fasciculata and reticularis showed a tendency to rise ac- cording to age, the gradient of the enhancement was not so remarkable as that of G-6-PD.

Zona glomerulosa: There was no change in Stage I in any of 10 cases. In Stage II among 9 cases, 5 showed increasing tendency of the activity with 3 of these showing slightly positive (Figs. 5, 6). The others showed no change. In Stage III, among 7 males, 3 showed a moderate increase while 4 did not change. As far as TPND activity in the glomerulosa is concerned, about half of the cases showed an increase both in Stages II and III. There was no definite tendency as in the case of G-6-PD activity. The increasing degree in TPND activity in the glomerulosa was less than in the fasciculata and reticularis and the intensity of the increase was not different between Stages II and III.

The findings of the TPND activity are summarized in Table $\mathrm{V}$.

3) Noradrenalin Reaction for the Adrenal Medulla. (Table VI, Figs. 7-10).

a) Histochemical findings: Noradrenalin reaction positive cell islets was identified scat-

Japanese Circulation Journal Vol. 3o, June 1966 
Table V Total Average Values of TPND Activity in the Adrenal Cortex

\begin{tabular}{|c|c|c|c|c|c|c|c|c|c|c|}
\hline \multirow{3}{*}{\multicolumn{2}{|c|}{$\begin{array}{c}\text { Experi- } \\
\text { mental } \\
\text { Stage }\end{array}$}} & \multirow{3}{*}{$\operatorname{Sex}$} & & \multirow{3}{*}{$\begin{array}{c}\text { No. of } \\
\text { Animals }\end{array}$} & $\mid \begin{array}{c}\text { Mean Systolic } \\
\text { Blood } \\
\text { Procso }\end{array}$ & \multirow{3}{*}{$\begin{array}{l}\text { Duration } \\
\text { of } \\
\text { Hyper- } \\
\text { tension } \\
\text { (day) }\end{array}$} & \multirow{2}{*}{$\begin{array}{c}\text { Mean Body } \\
\text { Weight at } \\
\text { Sacrifice } \\
(\text { gm })\end{array}$} & \multirow{3}{*}{$\begin{array}{c}\text { Adrenals } \\
\text { Weight/ } \\
\text { Body } \\
\text { Weight } \\
\frac{g m}{g m} \times 10^{5}\end{array}$} & \multicolumn{2}{|c|}{ Findings } \\
\hline & & & & & $\begin{array}{l}\text { at Sacrifice } \\
(\mathrm{mm} \mathrm{Hg})\end{array}$ & & & & \multirow{2}{*}{\begin{tabular}{|c|} 
Z. fasci- \\
culata \\
and \\
reticula- \\
ris
\end{tabular}} & \multirow{2}{*}{$\begin{array}{l}\text { Z. glome- } \\
\text { rulosa }\end{array}$} \\
\hline & & & & & mean S.D. & & mean (range) & & & \\
\hline \multirow[t]{2}{*}{$I$} & \multirow{2}{*}{$\begin{array}{l}42-59 \\
\text { Days } \\
\text { Old }\end{array}$} & \multirow[t]{2}{*}{$\delta$} & $\begin{array}{l}\text { Normotensive } \\
\text { Control }\end{array}$ & 10 & $116 \pm 6.8$ & 0 & $138 \quad(80-172)$ & $24.5 \pm 6.6$ & & \\
\hline & & & SHR & 10 & $136 \pm 7.2 * *$ & 0 & $124(80-164)$ & $26.0 \pm 8.5$ & & \\
\hline \multirow[t]{2}{*}{$I I$} & \multirow{2}{*}{$\begin{array}{l}5-7 \\
\text { Months } \\
\text { of Age }\end{array}$} & \multirow[t]{2}{*}{$\hat{\jmath}$} & $\begin{array}{c}\text { Normotensive } \\
\text { Control }\end{array}$ & 9 & $124 \pm 7.0$ & 0 & $306(250-368)$ & $12.7 \pm 3.1$ & \multirow{2}{*}{$\uparrow$} & \\
\hline & & & $S H R$ & 9 & $215 \pm 16.7 * *$ & $61-124$ & $247(170-282)$ & $19.3 \pm 7.7^{+}$ & & \\
\hline \multirow[t]{2}{*}{$I I I$} & \multirow{2}{*}{$\begin{array}{r}13-17 \\
\text { Months } \\
\text { of Age }\end{array}$} & \multirow{2}{*}{$\hat{\delta}$} & \begin{tabular}{|} 
Normotensive \\
Control
\end{tabular} & 7 & $120 \pm 5.2$ & 0 & $344(275-410)$ & $11.6 \pm 2.4$ & & \\
\hline & & & $S H R$ & 7 & $199 \pm 7.5 * *$ & $328-453$ & $347(320-374)$ & $11.8 \pm 2.1$ & & \\
\hline
\end{tabular}

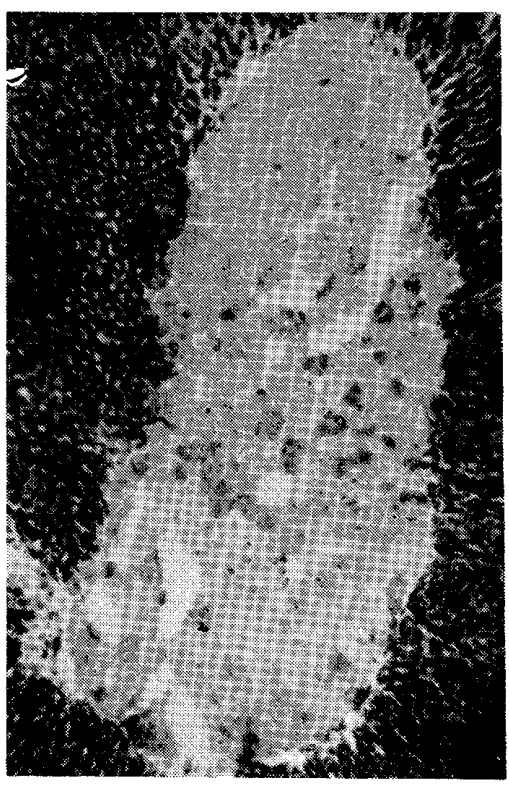

Fig. 7. Noradrenalin reaction for the adrenal medulla of a normotensive rat (No. 382, male, 51 days old). (By glutaraldehyde-osmium tetroxide technique). $(\times 40)$. Noradrenalin-storing cell islets are identified scattered in the adrenal medulla.

tered in the adrenal medulla of both the $\mathrm{N}$ and $\mathrm{SH}$ groups (Figs. 7-10). The intensity of the reaction was similar in the $\mathrm{N}$ group through all stages, but the number and size of reaction positive cell islets showed slightly an increasing tendency according to age. Usually in the hypertensives, from the pre-hypertensive stage, the reaction-positive cell islets in the adrenal medulla appeared larger, more numer-

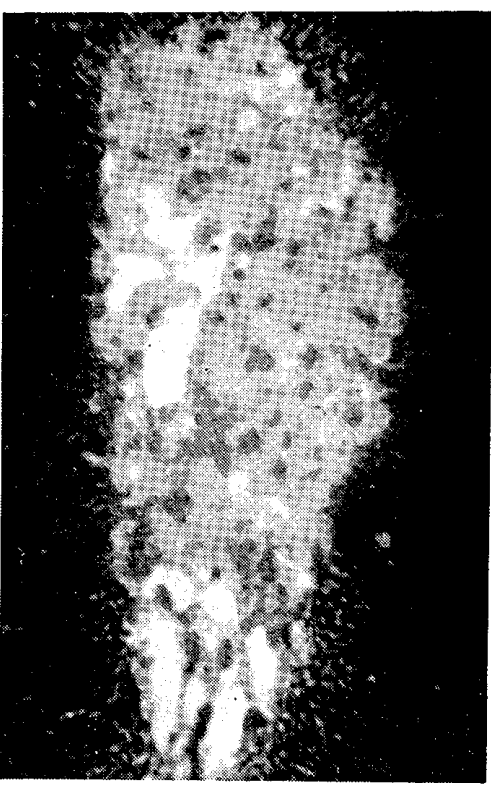

Fig. 8. Noradrenalin reaction for the adrenal medulla of a SH rat (No. 10056, male, 56 days old, prehypertensive stage). (By glutaraldehydeosmium tetroxide technique). $(\times 40)$. The noradrenalin-storing cell islets appear larger and more numerous.

ous and more densely stained. These tendencies became most intense in Stage III.

b) Histometrical findings: As shown in Table VII, the dimensional ratio of these reaction positive cell islets to the whole adrenal medulla of the $\mathrm{N}$ group was 11.0 per cent in Stage I, 13.3 per cent in Stage II and 14.8 per cent in Stage III. Thus the dimensional ratio in the $\mathrm{N}$ group histometrically 

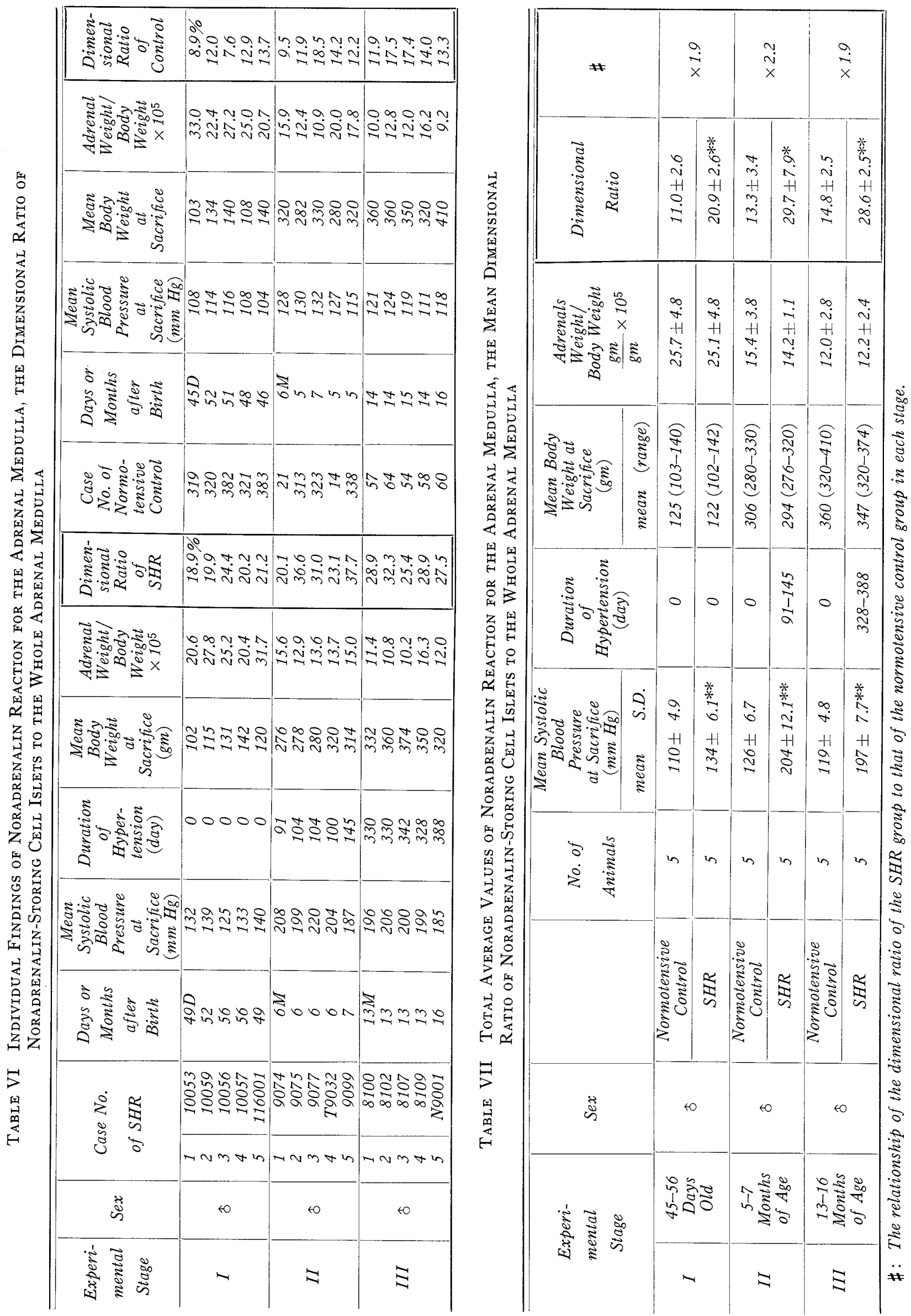

Japanese Circulation Journal Vol. 3o, June 1966 


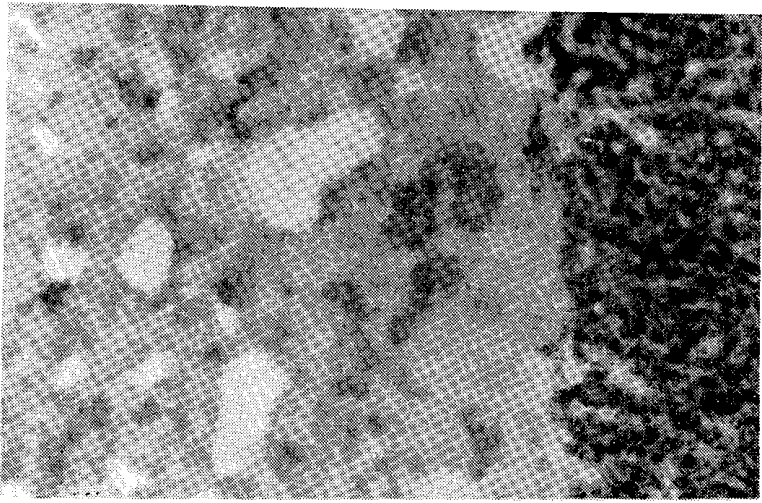

Fig. 9. Noradrenalin reaction for the adrenal medulla of a normotensive rat (No. 323, male, 7 months of age). (By glutaraldehyde-osmium tetroxide technique). $(\times 100)$. Noradrenalin-storing cell islets are scattered in the medulla. On the right side a part of the cortex can be seen. also increased slightly according to age. On the other hand, that of the $\mathrm{SH}$ group was found to be 20.9 per cent in Stage I corresponding to about 1.9 times that of the mean of the $\mathrm{N}$ group in the same stage. In Stage II, the mean was shown to be 29.7 per cent corresponding to about 2.2 times compared to that of the $\mathrm{N}$ group of the same age. In Stage III, the SH group mean was 28.6 per cent, about 1.9 times compared to that of the $\mathrm{N}$ group. Thus the mean dimensional ratio of noradrenalin-storing cell islets to the whole adrenal medulla of the SH group showed about twice that of each corresponding $\mathrm{N}$ group through all the stages from I to III. There was no plain interrelationship between the severity of hypertension and the intensity of reaction in the adrenal medulla of the SH group within each stage.

4) ACPase Activity in the Follicular Cells of the Thyroid. (Table VIII, Figs. 11, 12). The activity was recognized by the presence of reaction product in the cytoplasma of follicular epithelial cells of the thyroid both in the $\mathrm{N}$ and $\mathrm{SH}$ groups. Thyroid sections of the $\mathrm{N}$ group showed moderately positive reaction in the follicular cells through all stages and had follicles, showing rather strongly stained epithel, scattered among moderately positive ones. On the other hand, in the $\mathrm{SH}$ group, almost all the follicular epithel demon-

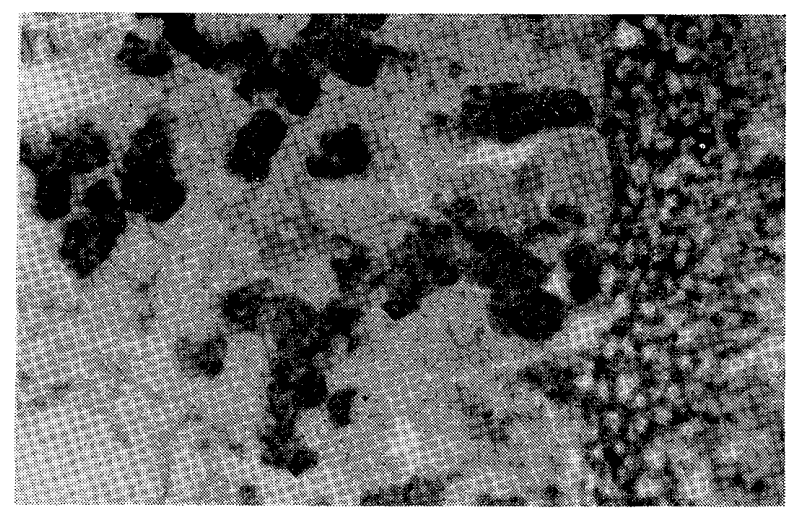

Fig. 10. Noradrenalin reaction for the adrenal medulla of a SH rat (No. 9077, male, 6 months of age, initial stage of hypertenson). (By glutaraldehyde-osmium tetroxide technique). $(\times 100)$. Noradrenalin-storing cell islets in the medulla indicate a stronger reaction with about twice the dimensional ratio to the whole adrenal medulla histometrically.

strated stronger average activity. In Stage I, all 7 cases displayed a clear increase, 3 markedly and the others moderately. In Stages II and III, all cases had a distinct increasing tendency with 6 in Stage II and 4 in Stage III respectively marked (Figs. 11, 12).

The findings of ACPase activity in the thyroid are summarized in Table IX. The increase was observed in the $\mathrm{SH}$ group through all stages and became more definite in Stages II and III.

5) ATPase Activity in the Vasa Afferens and Interlobular Arteries of the Kidney. (Table $\mathrm{X}$, Figs. 13-16). In the kidney of the $\mathrm{N}$ group, ATPase activity was remarkably detected in the vascular walls such as the arcuate and interlobular arteries, vasa afferens and glomerular capillaries through all stages. The activity was almost the same in all vascular walls.

Vasa afferens: In the $\mathrm{SH}$ group, the activity was no different in any case in Stage I, but all of 10 cases in Stage II and all of 9 in Stage III showed an increase (Figs. 13, 14).

Interlobular arteries: In the $\mathrm{SH}$ group, among 9 cases in Stage I, 4 showed no change and 5 increased moderately. All SH rats in Stages II and III showed increase, 3 out of 10 in Stage II, 5 out of 9 in Stage III displaying marked increase (Figs. 15, 16). In Stage II, there was no distinct interrelationship between the severity and duration of hypertension and 


\begin{tabular}{|c|c|c|c|}
\hline 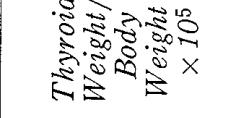 & 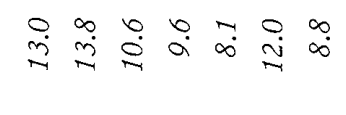 & 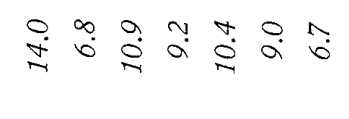 & 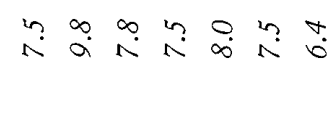 \\
\hline 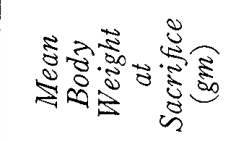 & 윤 & ڤి & 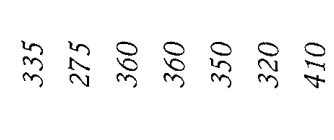 \\
\hline 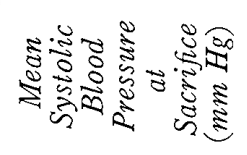 & 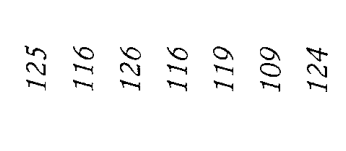 & 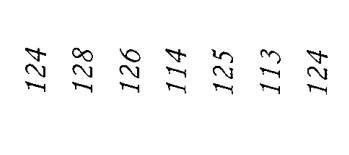 & 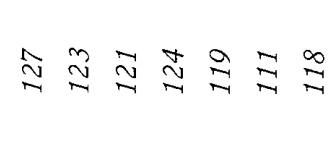 \\
\hline 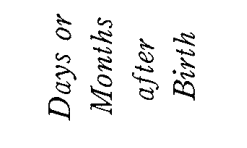 & 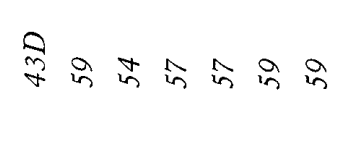 & I 0 b 0 in in in & 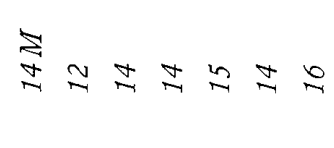 \\
\hline 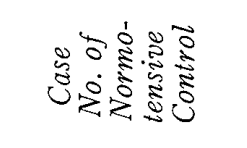 & 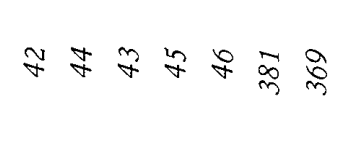 & 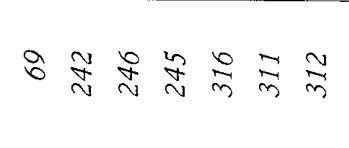 & $\stackrel{m}{2} \prod_{n}$ in \\
\hline 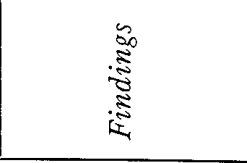 & $\leftleftarrows \leftarrow \leftarrow \leftleftarrows E \leftarrow \leftarrow$ & $\leftleftarrows: \leftleftarrows \leftleftarrows: \leftleftarrows \leftarrow$ & $\leftarrow \leftleftarrows \leftarrow \leftleftarrows \leftarrow \leftleftarrows E$ \\
\hline 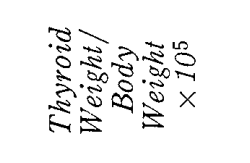 & 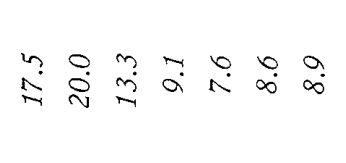 & 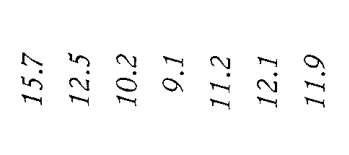 & 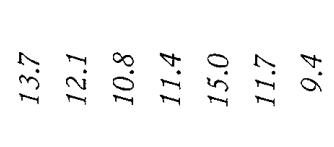 \\
\hline 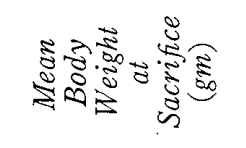 & 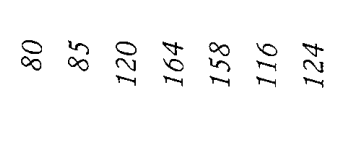 & 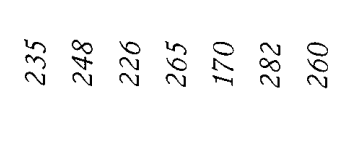 & 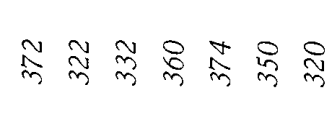 \\
\hline 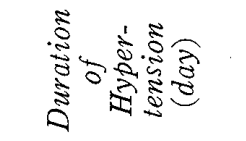 & 0000000 & 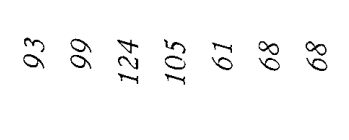 & 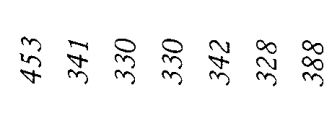 \\
\hline 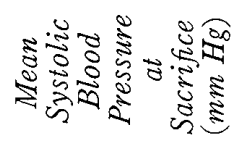 & 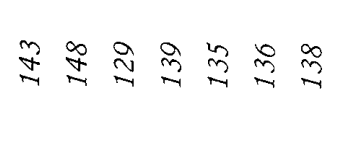 & 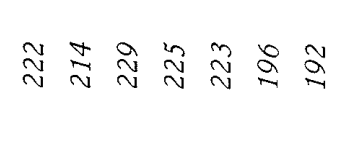 & 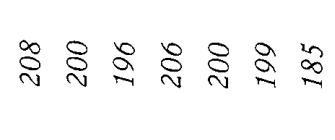 \\
\hline 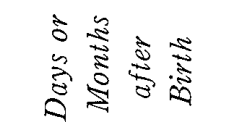 & 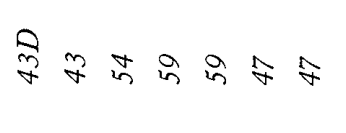 & I 0 b 0 n n n m & 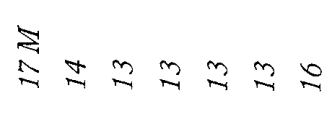 \\
\hline 完选 & 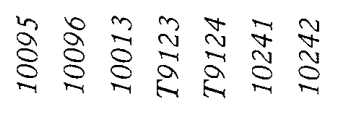 & 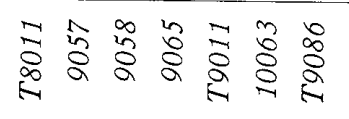 & 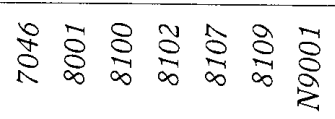 \\
\hline $3^{3} 0$ & $\pi v m+n o x$ & $r v m+i b N$ & $\sim v m+n b N$ \\
\hline હ్ّ & ↔ & to & $\leftrightarrow$ \\
\hline 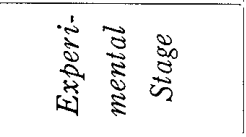 & - & $\approx$ & $\Xi$ \\
\hline
\end{tabular}




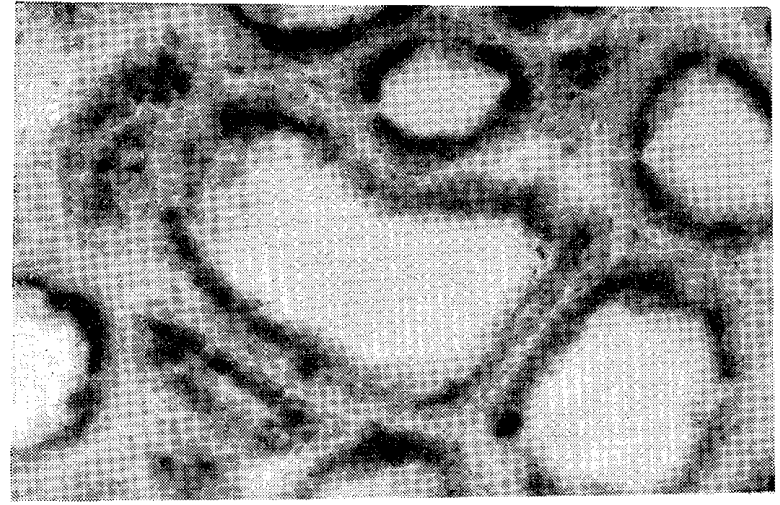

Fig. 11. ACPase activity in the follicular cells of the thyroid of a normotensive rat (No. 242, male, 6 months of age). (By metal-salt method). $(\times 400)$. The follicular epithel cells show moderately positive reaction.

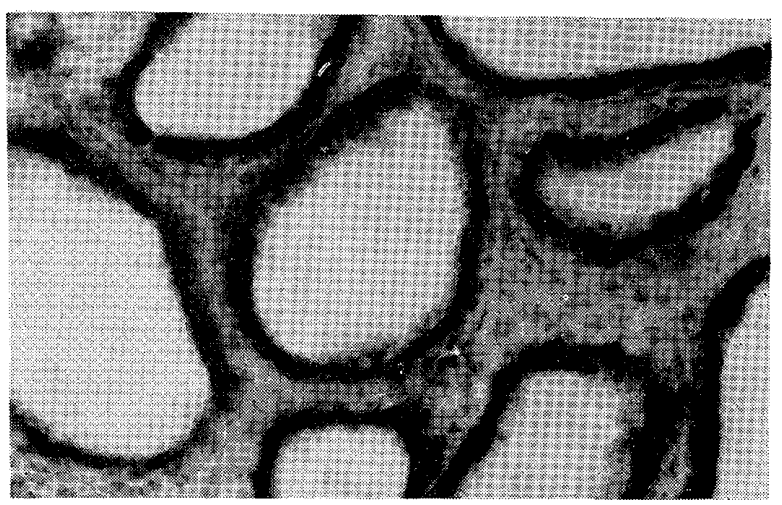

Fig. 12. ACPase activity in the follicular cells of the thyroid of a $\mathrm{SH}$ rat (No. 9057, male, 6 months of age, initial stage of hypertension). (By metal-salt method). $(\times 400)$. The follicular epithel displays a marked increase of the activity compared to the control (Fig. 11).

Table IX Total Average Values of ACPase Activity in the Thyroid

\begin{tabular}{|c|c|c|c|c|c|c|c|c|c|}
\hline \multirow{2}{*}{\multicolumn{2}{|c|}{$\begin{array}{l}\text { Experi- } \\
\text { mental } \\
\text { Stage }\end{array}$}} & \multirow[t]{2}{*}{ Sex } & & \multirow[t]{2}{*}{$\begin{array}{c}\text { No. of } \\
\text { Animals }\end{array}$} & $\begin{array}{c}\text { Mean Systolic } \\
\text { Blood } \\
\text { Pressure } \\
\text { at Sacrifice } \\
(\mathrm{mm} \mathrm{Hg})\end{array}$ & \multirow[t]{2}{*}{$\begin{array}{c}\text { Duration } \\
\text { of } \\
\text { Hyper- } \\
\text { tension } \\
\text { (day) }\end{array}$} & $\begin{array}{c}\text { Mean Body } \\
\text { Weight at } \\
\text { Sacrifice } \\
(\mathrm{gm})\end{array}$ & \multirow{2}{*}{$\begin{array}{c}\text { Thyroid } \\
\text { Weight/ } \\
\text { Body } \\
\text { Weight } \\
\frac{g m}{g m} \times 10^{5}\end{array}$} & \multirow[t]{2}{*}{ Findings } \\
\hline & & & & & mean S.D. & & mean (range) & & \\
\hline \multirow{2}{*}{$I$} & \multirow{2}{*}{$\begin{array}{l}43-59 \\
\text { Days } \\
\text { Old }\end{array}$} & \multirow{2}{*}{$\hat{o}$} & $\begin{array}{c}\text { Normotensive } \\
\text { Control }\end{array}$ & 7 & $119 \pm 6.2$ & 0 & $143(80-172)$ & $10.9 \pm 2.2$ & \multirow{2}{*}{$\uparrow \uparrow$} \\
\hline & & & $S H R$ & 7 & $138 \pm 6.1$ & 0 & $121(80-164)$ & $12.2 \pm 4.9$ & \\
\hline \multirow{2}{*}{$I I$} & \multirow{2}{*}{$\begin{array}{c}5-7 \\
\text { Months } \\
\text { of Age }\end{array}$} & \multirow{2}{*}{$\delta$} & $\begin{array}{c}\text { Normotensive } \\
\text { Control }\end{array}$ & 7 & $119 \pm 6.2$ & 0 & $307(250-368)$ & $10.9 \pm 2.2$ & \multirow{2}{*}{$\uparrow \uparrow$} \\
\hline & & & $S H R$ & 7 & $216 \pm 14.8^{* * *}$ & $61-124$ & $241(170-282)$ & $11.8 \pm 2.1$ & \\
\hline \multirow{2}{*}{$I I I$} & \multirow{2}{*}{$\begin{array}{l}13-17 \\
\text { Months } \\
\text { of Age }\end{array}$} & \multirow[t]{2}{*}{$\delta$} & $\begin{array}{c}\text { Normotensive } \\
\text { Control }\end{array}$ & 7 & $120 \pm 5.2$ & 0 & $344(275-410)$ & $7.8 \pm 1.0$ & \multirow{2}{*}{$\uparrow \uparrow$} \\
\hline & & & $S H R$ & 7 & $199 \pm 7.5^{* * *}$ & $328-453$ & $347(320-374)$ & $12.0 \pm 1.8 * *$ & \\
\hline
\end{tabular}

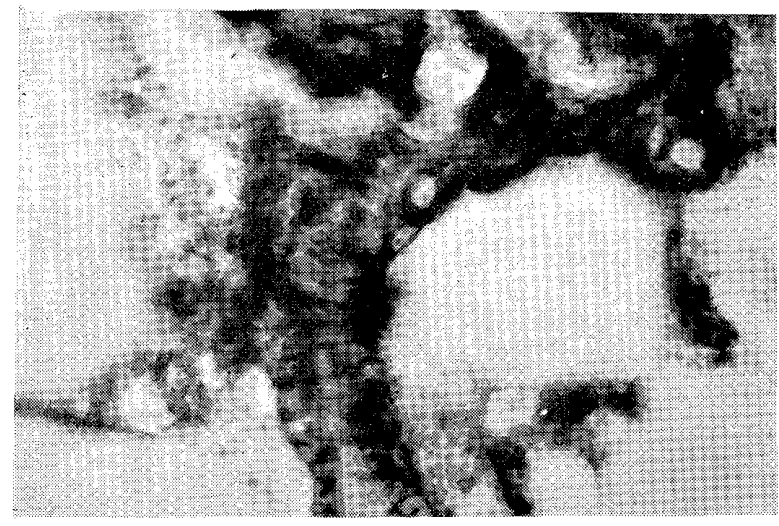

Fig. 13. ATPase activity in the vasa afferens of the kidney of a normotensive rat (No. 69, male, 6 months of age). (By metal-salt method). $(\times 400)$. The activity is shown in the walls of a vas afferens.

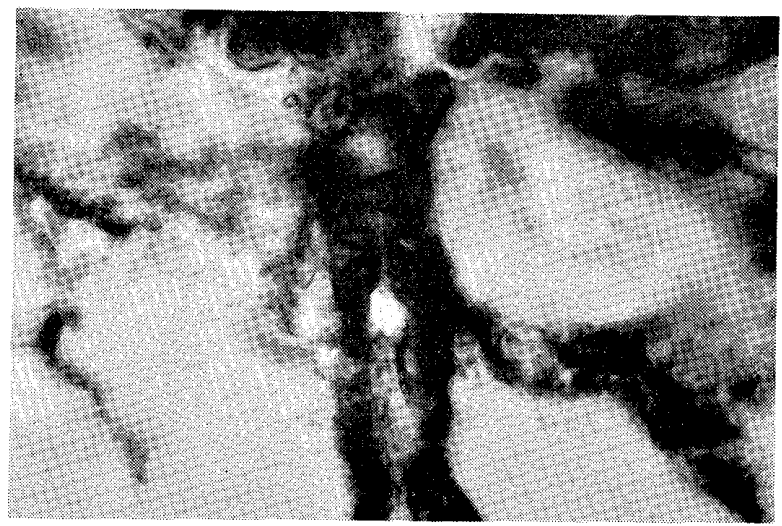

Fig. 14. ATPase activity in the vasa afferens of the kidney of a SH rat (No. T8011, male, 7 months of age, initial stage of hypertension). (By metal-salt method). $(\times 400)$. A stronger activity is observed compared to the control (Fig.13).

Japanese Circulation Journal Vol. 3o, June 1966 


\begin{tabular}{|c|c|c|c|c|}
\hline 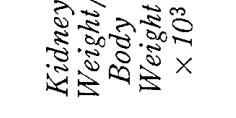 & 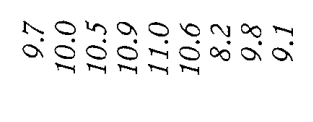 & 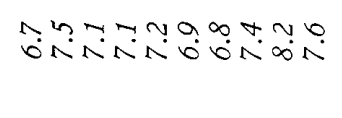 & 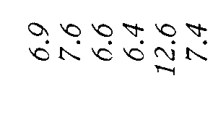 & 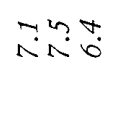 \\
\hline 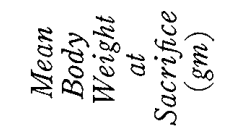 & 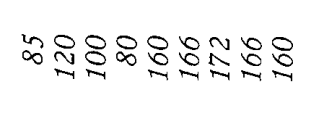 & 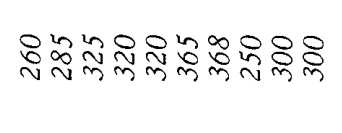 & WÑ & 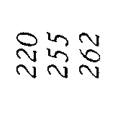 \\
\hline 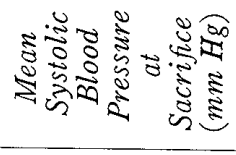 & 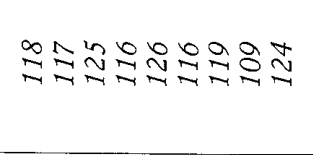 & 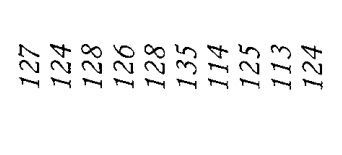 & 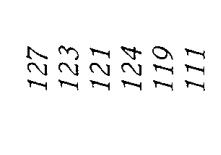 & $\stackrel{2}{\beth} \underset{N}{N}$ \\
\hline 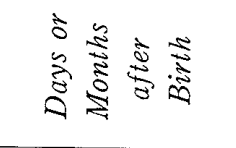 & 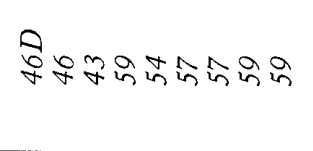 & 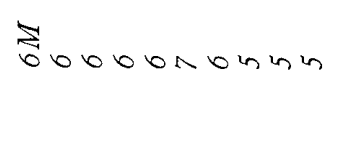 & オクンボン & $2 \pm \pm$ \\
\hline 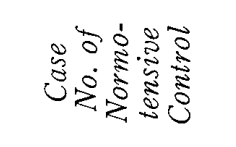 & 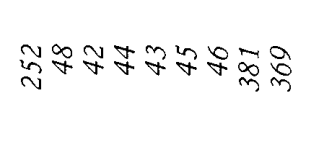 & 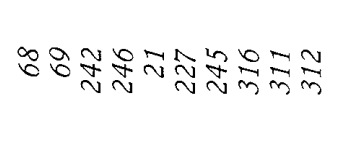 & 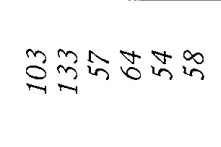 & 고워요 \\
\hline 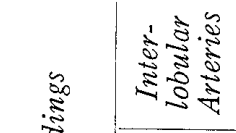 & $\leftarrow \leftarrow \leftarrow-\uparrow \uparrow \uparrow \uparrow \leftrightarrow$ & $\leftarrow \leftarrow \leftarrow \leftarrow \leftarrow \leftarrow \leftarrow \leftarrow \leftarrow$ & $E \leftarrow \leftarrow \leftleftarrows \leftarrow \leftleftarrows$ & $\leftarrow \leftarrow$ \\
\hline 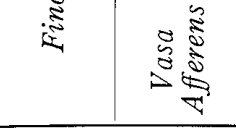 & $\uparrow \uparrow \uparrow \uparrow \uparrow \uparrow \uparrow \uparrow \uparrow$ & $\leftarrow \leftarrow: \leftarrow \leftarrow \leftarrow \leftarrow \leftarrow \leftarrow$ & $\hookleftarrow \leftarrow \leftarrow \leftarrow$ & $\leftarrow \leftarrow$ \\
\hline 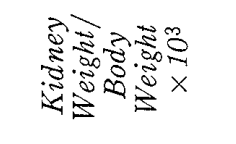 & 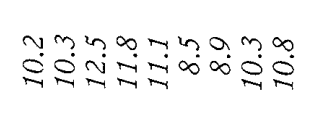 & 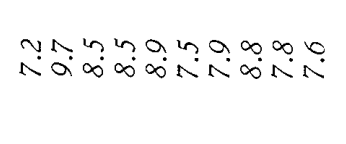 & 우요 & $\stackrel{\infty}{\wedge} \stackrel{\infty}{\wedge}$ \\
\hline 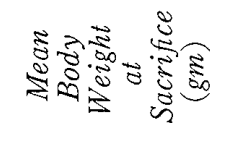 & 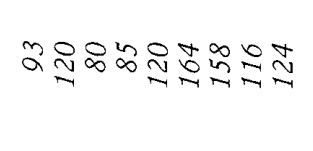 & 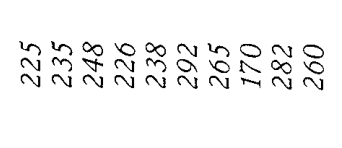 & 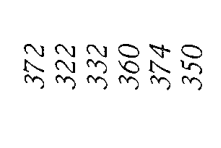 & 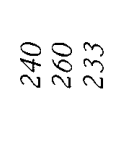 \\
\hline 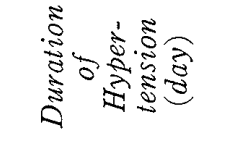 & 000000000 & 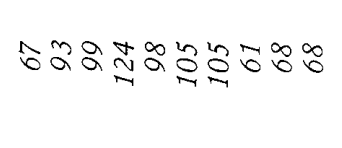 & 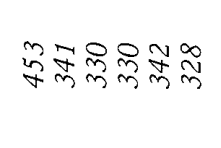 & लेస̃ \\
\hline 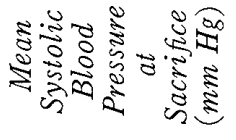 & 옥 & 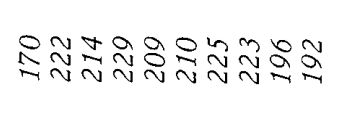 & 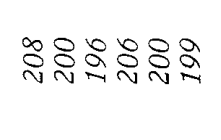 & 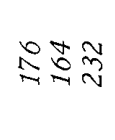 \\
\hline 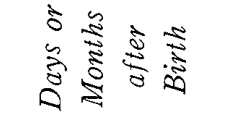 & 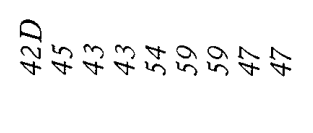 & Int 00000 ing in & 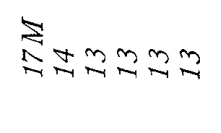 & \pm 0 \\
\hline \multirow{2}{*}{ 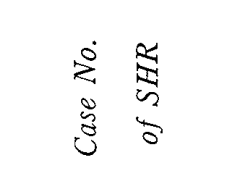 } & 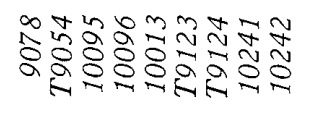 & 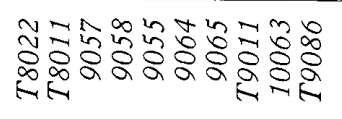 & 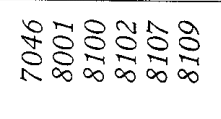 & 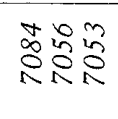 \\
\hline & rvmanonsa & rNmanos & ramano & $\wedge \infty a$ \\
\hline 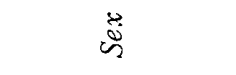 & to & to & 七o & or \\
\hline 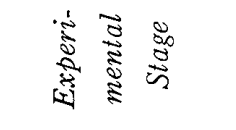 & - & $\approx$ & $\Xi$ & \\
\hline
\end{tabular}




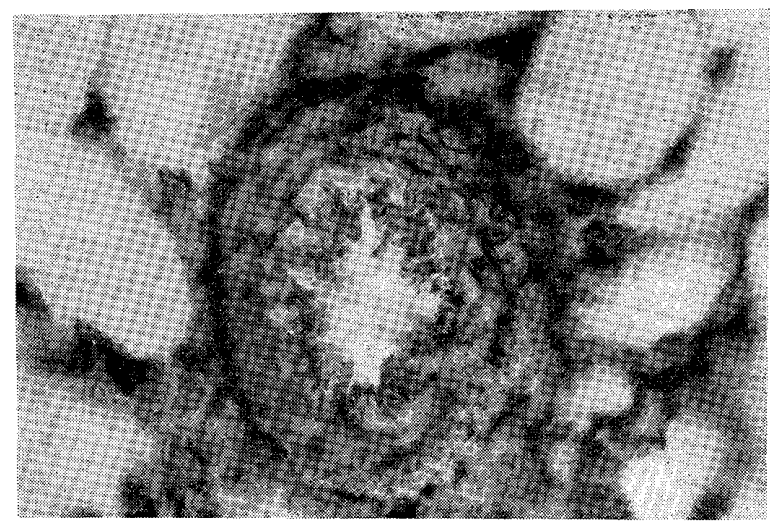

Fig. 15. ATPase activity in the renal interlobular arteries of a normotensive rat (No. 21, male, 6 months of age). (By metal-salt method). $(\times 400)$. The activity is detected in the wall of the vessel.

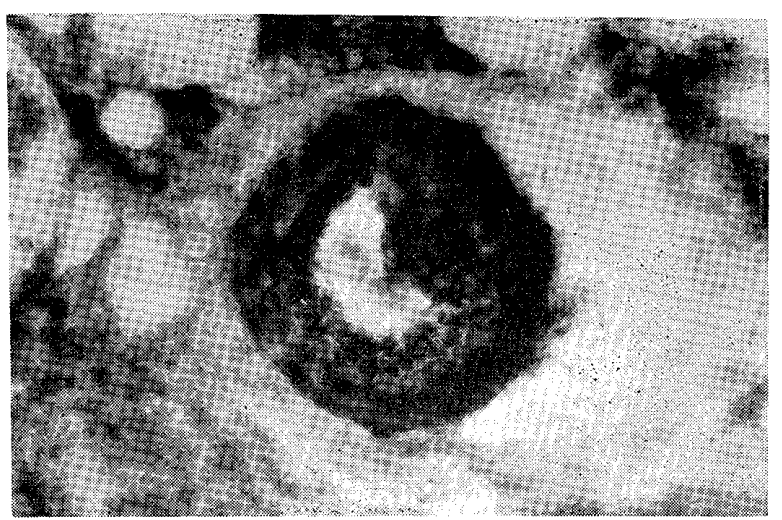

Fig. 16. ATPase activity in the renal interlobular arteries of a SH rat (No. 9055, male, 6 months of age, initial stage of hypertension). (By metal-salt method). $(\times 400)$. Marked increase of the activity is observed compared to the control (Fig. 15).

Table Xi Total Average Values of ATPase Activity in the Renal Vessels

\begin{tabular}{|c|c|c|c|c|c|c|c|c|c|c|}
\hline \multirow{3}{*}{\multicolumn{2}{|c|}{$\begin{array}{c}\text { Experimental } \\
\text { Stage }\end{array}$}} & \multirow{3}{*}{ Sex } & & \multirow{3}{*}{$\begin{array}{c}\text { No. of } \\
\text { Animals }\end{array}$} & \multirow{2}{*}{$\begin{array}{c}\text { Mean Systolic } \\
\text { Blood } \\
\text { Pressure } \\
\text { at Sacrifice } \\
(\mathrm{mm} \mathrm{Hg})\end{array}$} & \multirow{3}{*}{\begin{tabular}{|} 
Duration \\
of \\
Hyper- \\
tension \\
(day)
\end{tabular}} & \multirow{2}{*}{$\begin{array}{c}\text { Mean Body } \\
\text { Weight at } \\
\text { Sacrifice } \\
\text { (gm) }\end{array}$} & \multirow{3}{*}{$\begin{array}{c}\text { Kidneys } \\
\text { Weight } \\
\text { Body } \\
\text { Weight } \\
\frac{g m}{g m} \times 10^{3}\end{array}$} & \multicolumn{2}{|c|}{ Findings } \\
\hline & & & & & & & & & \multirow[t]{2}{*}{$\begin{array}{c}\text { Vasa } \\
\text { Afferens }\end{array}$} & \multirow{2}{*}{$\begin{array}{l}\text { Inter- } \\
\text { lobular } \\
\text { Arteries }\end{array}$} \\
\hline & & & & & mean S.D. & & mean (range) & & & \\
\hline \multirow[t]{2}{*}{$I$} & \multirow{2}{*}{$\begin{array}{l}42-59 \\
\text { Days } \\
\text { Old }\end{array}$} & \multirow{2}{*}{$\hat{\delta}$} & $\begin{array}{c}\text { Normotensive } \\
\text { Control }\end{array}$ & 9 & $119 \pm 5.4$ & 0 & $134(80-172)$ & $10.0 \pm 0.9$ & \multirow{2}{*}{ 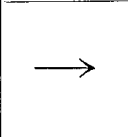 } & \multirow{2}{*}{$\uparrow$} \\
\hline & & & $S H R$ & 9 & $138 \pm 5.6^{* *}$ & 0 & $118(80-164)$ & $10.5 \pm 1.3^{+}$ & & \\
\hline \multirow{2}{*}{$I I$} & \multirow{2}{*}{$\begin{array}{c}5-7 \\
\text { Months } \\
\text { of Age }\end{array}$} & \multirow[t]{2}{*}{$\hat{\delta}$} & $\begin{array}{c}\text { Normotensive } \\
\text { Control }\end{array}$ & 10 & $124 \pm 6.5$ & 0 & $309(25 c-368)$ & $7.3 \pm 0.4$ & \multirow{2}{*}{$\uparrow$} & \multirow[t]{2}{*}{$\uparrow$} \\
\hline & & & $S H R$ & 10 & $209 \pm 18.4 * *$ & $61-124$ & $244(170-292)$ & $8.3=0.8 * \cdots$ & & \\
\hline \multirow{4}{*}{$I I I$} & \multirow{4}{*}{$\begin{array}{l}\text { 13-17 } \\
\text { Months } \\
\text { of Age }\end{array}$} & \multirow{2}{*}{$\hat{\delta}$} & $\begin{array}{c}\text { Normotensive } \\
\text { Control }\end{array}$ & 6 & $121 \pm 5.5$ & 0 & $333(275-360)$ & $7.9 \pm 2.3$ & \multirow{2}{*}{$\uparrow$} & \multirow{2}{*}{$\uparrow \uparrow$} \\
\hline & & & SHR & 6 & $202 \pm 4.6 * *$ & $328-453$ & $352(322-374)$ & $8.1 \pm 0.7$ & & \\
\hline & & \multirow[b]{2}{*}{ q } & $\begin{array}{l}\text { Normotensive } \\
\text { Control }\end{array}$ & 3 & $125 \doteq 0.2$ & 0 & $246(220-262)$ & $7.0 \pm 0.5$ & \multirow{2}{*}{$\uparrow$} & \multirow[t]{2}{*}{$\uparrow$} \\
\hline & & & SHR & 3 & $191 \pm 36.3^{+}$ & $323-461$ & $244(233-260)$ & $8.1 \pm 0.5$ & & \\
\hline
\end{tabular}

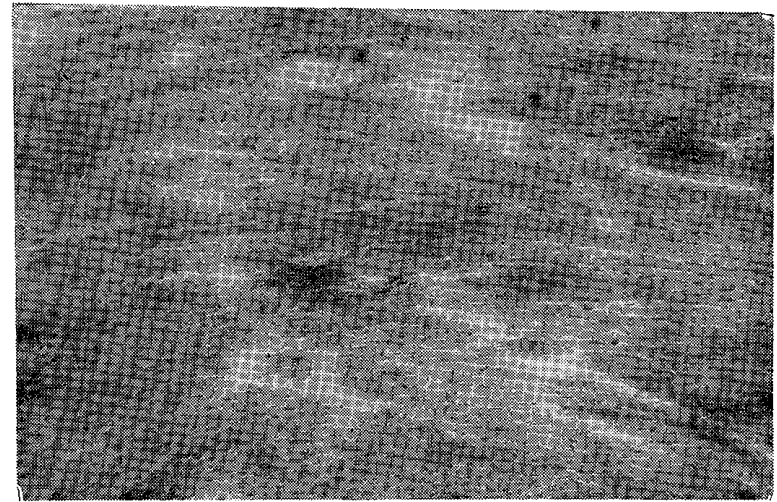

Fig. 17. MAO activity in the heart muscle of a normotensive rat (No. 109, female, 14 months of age). (By tetrazolium method). ( $\times 100)$. The reaction is observed rather diffusely in the heart muscle.

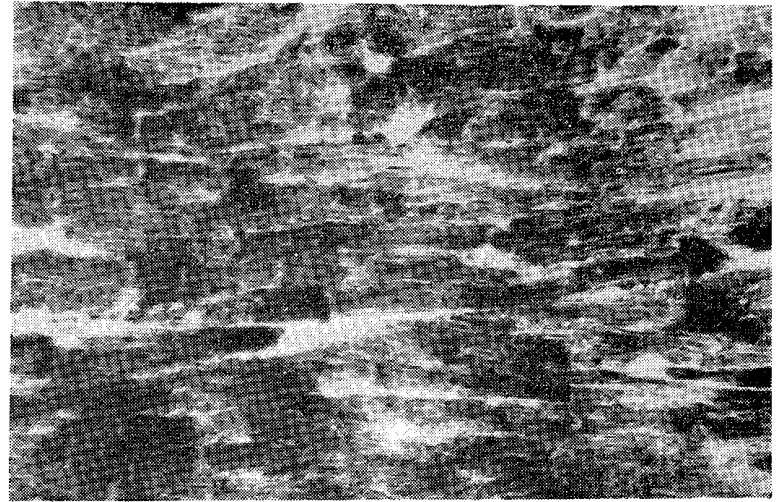

Fig. 18. MAO activity in the heart muscle of a SH rat (NO. 7053, female, 17 months of age). (By tetrazolium method $)$. $(\times 100)$. Prominent elevation of the activity is observed.

Japanese Circulation Journal Vol. 3o, June $x 966$ 


\begin{tabular}{|c|c|c|c|c|}
\hline 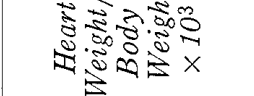 & 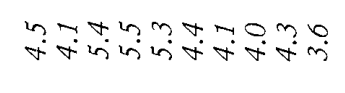 & 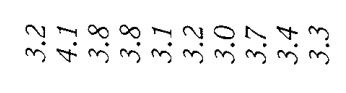 & $\hat{m} \dot{m} \dot{m} \nabla \dot{m} \dot{m} \dot{m}$ & 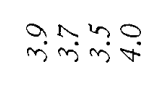 \\
\hline 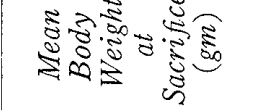 & 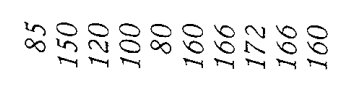 & 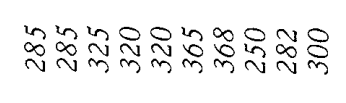 & 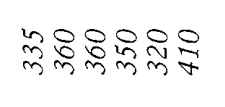 & 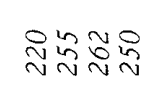 \\
\hline 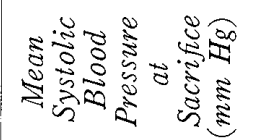 & 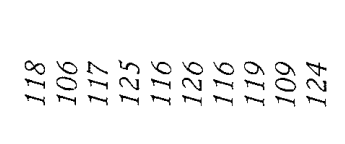 & 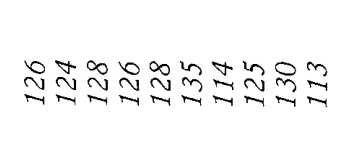 & 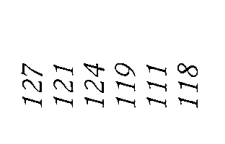 & 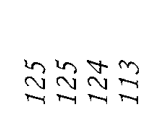 \\
\hline 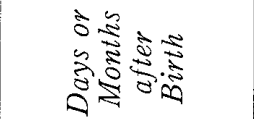 & 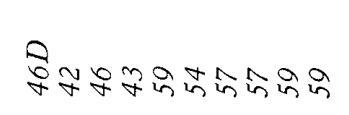 & SHoboonoming & 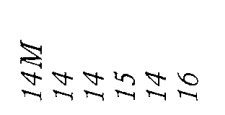 & 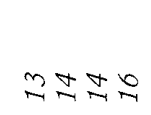 \\
\hline 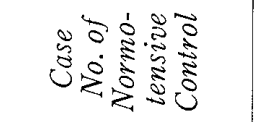 & 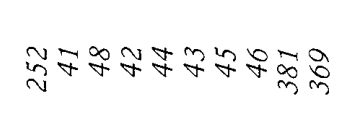 & 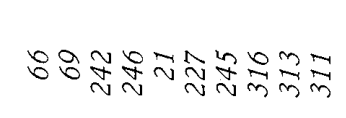 & 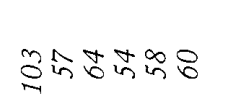 & 측을을 \\
\hline 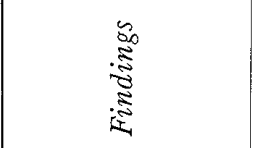 & $\leftrightarrow \rightarrow \uparrow \leftrightarrow \uparrow \uparrow \uparrow \rightarrow \rightarrow \rightarrow \rightarrow$ & $\leftleftarrows \leftarrow \leftarrow \leftarrow \leftarrow \leftarrow \leftarrow \leftarrow \leftarrow \leftarrow$ & 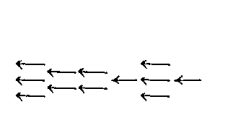 & $\leftarrow \leftleftarrows \Xi$ \\
\hline 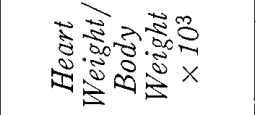 & 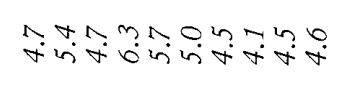 & 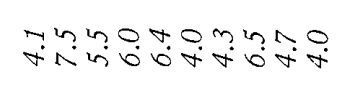 & 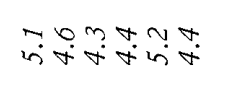 & 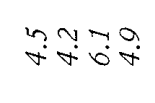 \\
\hline 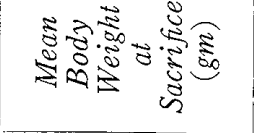 & 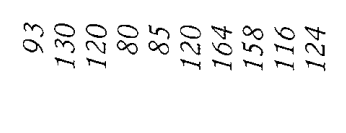 & 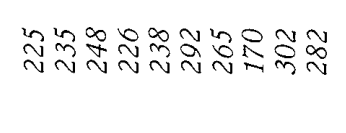 & 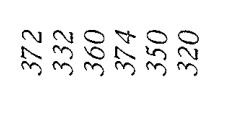 & 용ำ \\
\hline 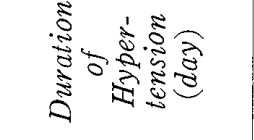 & 0000000000 & 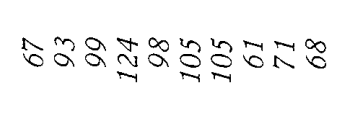 & 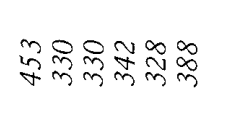 & 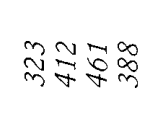 \\
\hline 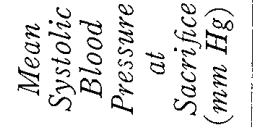 & 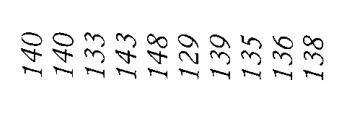 & 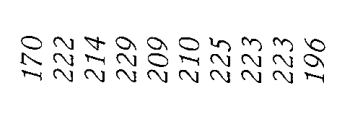 & 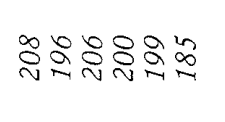 & 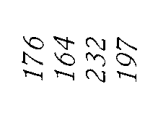 \\
\hline 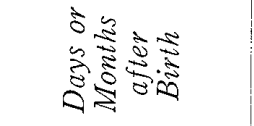 & 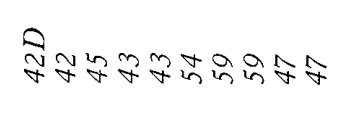 & जintoboboing in & 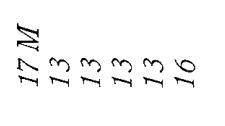 & 문으순 \\
\hline 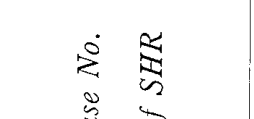 & 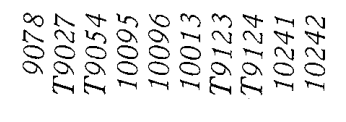 & 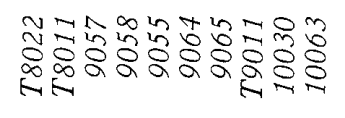 & 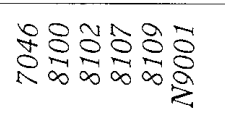 & 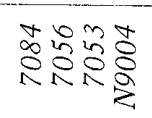 \\
\hline & 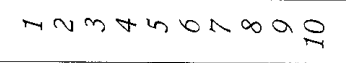 & rvmonbnoa? & $\operatorname{rom} \sin 0$ & $n \infty a ?$ \\
\hline ڤ్ & $\leftrightarrow$ & to & to & ot \\
\hline 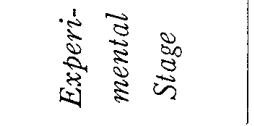 & - & $\approx$ & $\Xi$ & \\
\hline
\end{tabular}

Japanese Circulation Icurnal Vol. 30, June 1966 
Table XiII Total Average Values of MAO Activity in the Heart Muscle

\begin{tabular}{|c|c|c|c|c|c|c|c|c|c|}
\hline \multirow{2}{*}{\multicolumn{2}{|c|}{$\begin{array}{l}\text { Experi- } \\
\text { mental } \\
\text { Stage }\end{array}$}} & \multirow[t]{2}{*}{$\operatorname{Sex}$} & & \multirow[t]{2}{*}{$\begin{array}{c}\text { No. of } \\
\text { Animals }\end{array}$} & $\begin{array}{c}\text { Mean Systolic } \\
\text { Blood } \\
\text { Pressure at } \\
\text { Sacrifice } \\
(m m H g) \\
\end{array}$ & \multirow[t]{2}{*}{$\begin{array}{c}\text { Duration } \\
\text { of } \\
\text { Hyper- } \\
\text { tension } \\
\text { (day) }\end{array}$} & $\begin{array}{c}\text { Mean Body } \\
\text { Weight at } \\
\text { Sacrifice } \\
(\mathrm{gm}) \\
\end{array}$ & \multirow[t]{2}{*}{$\begin{array}{c}\text { Heart } \\
\text { Weight/ } \\
\text { Body Weight } \\
\frac{g m}{g m} \times 10^{3}\end{array}$} & \multirow[t]{2}{*}{ Findings } \\
\hline & & & & & mean S.D. & & mean (range) & & \\
\hline \multirow[t]{2}{*}{$I$} & \multirow{2}{*}{$\begin{array}{c}42-59 \\
\text { Days } \\
\text { Old }\end{array}$} & \multirow{2}{*}{$\delta$} & $\begin{array}{c}\text { Normotensive } \\
\text { Control }\end{array}$ & 10 & $118 \pm 6.5$ & 0 & $136 \quad(80-172)$ & $4.5 \pm 0.7$ & \multirow{2}{*}{ Indefinite } \\
\hline & & & $S H R$ & 10 & $138 \pm 5.3 * *$ & 0 & $119(80-164)$ & $4.9 \pm 0.7$ & \\
\hline \multirow[t]{2}{*}{$I I$} & \multirow{2}{*}{$\begin{array}{c}5-7 \\
\text { Months } \\
\text { of Age }\end{array}$} & \multirow{2}{*}{$\delta$} & $\begin{array}{c}\text { Normotensive } \\
\text { Control }\end{array}$ & 10 & $125 \pm 6.8$ & 0 & $310(250-368)$ & $3.5 \pm 0.4$ & \\
\hline & & & $S H R$ & 10 & $212 \pm 17.8^{* *}$ & $61-124$ & $248(170-302)$ & $5.3 \pm 1.3 * *$ & \\
\hline \multirow{4}{*}{$I I I$} & \multirow{4}{*}{$\begin{array}{c}13-17 \\
\text { Months } \\
\text { of Age }\end{array}$} & \multirow{2}{*}{$\delta$} & \begin{tabular}{|c|} 
Normotensive \\
Control
\end{tabular} & 6 & $120 \pm 5.5$ & 0 & $356(320-410)$ & $3.6 \pm 0.2$ & \multirow{2}{*}{$\uparrow \uparrow$} \\
\hline & & & $S H R$ & 6 & $199 \pm 8.2 * *$ & $328-453$ & $351(320-374)$ & $4.7 \pm 0.4^{* *}$ & \\
\hline & & & $\begin{array}{c}\text { Normotensive } \\
\text { Control }\end{array}$ & 4 & $122 \pm 5.9$ & 0 & $247(220-262)$ & $3.8 \pm 0.2$ & \multirow{2}{*}{$\uparrow \uparrow$} \\
\hline & & & $S H R$ & 4 & $192 \pm 29.0 *$ & $323-461$ & $247(233-260)$ & $4.9 \pm 0.8^{+}$ & \\
\hline
\end{tabular}

intensity of reaction either in vasa afferens or interlobular arteries. In Stage III, there seemed to exist a parallel relationship between the severity of hypertension and the intensity of the activity increase in the renal interlobular arteries in both sexes.

Arcuate arteries and glomerular capillaries: The activity was unaltered through all stages.

The findings on the ATPase activity are summarized in Table XI.

6) MAO Activity in the Heart Muscle. (Table XII, Figs. 17, 18). In the N group, rats in Stage I showed a slightly positive reaction and had a tendency to stain slightly unevenly. The staining was somewhat stronger in the papillary muscles of the left ventricle. The reaction became more even and more diffuse in Stage II. The reaction became stronger and displayed quite diffusely in a section in Stage III (Figs. 17, 18). Thus the reaction grew more intense in the $\mathrm{N}$ group according to age. In the $\mathrm{SH}$ group, among 10 cases in Stage I, 4 showed no change, one moderately and another one slightly increased and 2 showed slightly and another 2 were moderately decrease in the activity when compared to the $\mathrm{N}$ group in Stage I. Thus $\mathrm{SH}$ group in Stage I showed no definite tendency. In Stages II and III, all cases displayed an increase of the activity. Among 10 cases in Stage II, 4 showed slight, another 4 moderate and 2 marked increase. Of a total of 10 cases in Stage III, 4 showed moderate, 2 marked and 4 most marked increase. The longer the duration of survival, the stronger the observed reaction in the heart of both the $\mathrm{N}$ and $\mathrm{SH}$ groups. The SH group had a greater proportion in increase of the activity than the $\mathrm{N}$ group, and displayed more dominant increase in Stage III than in Stage II.

The findings on MAO activity are summarized in Table XIII. No characteristic findings were observed in the position of the heart conducting system in any stage.

Some other additional findings are hereunder listed. In the $\mathrm{N}$ group, in all experimental histochemical groups, strength of the histochemical reaction had little fluctuation through all stages, except MAO activity. Variation according to sex in Stage III was not demonstrated in any kind of histochemical reaction.

Among $\mathrm{SH}$ rats, within each stage, interrelationship between the severity and duration of hypertension and the increasing degree of histochemical activity was not demonstrated except in renal interlobular arteries in Stage III.

Finally, in the adrenals, thyroid, kidneys and heart, no particular results were found in other kind of enzyme histochemistry save for 
those described above. Comparative histochemical tests of the liver and pancreas of rats in both groups produced no significant findings whatsoever.

\section{Discussion}

It has been in accord with reports concerning the $\mathrm{SH}$ rats that there is no significant difference in body weight between the animals of the $\mathrm{N}$ group and the $\mathrm{SH}$ group ${ }^{1 / 9) 13)}$. Blood pressure rose in almost all the $\mathrm{SH}$ rats from the pre-hypertensive stage and became significantly high after the development of hypertension. As shown in the present materials and as reported earlier ${ }^{1) 13)}$, the course of blood pressure of SH rats in Stage I (40-60 days old), in Stage II (5-7 months of age) and in Stage III (13-17 months of age) correspond to those in the pre-hypertensive stage, initial stage and advanced stage of hypertension respectively.

The above-mentioned comparative histochemical findings were obtained by the examination of twenty-one kinds of enzyme activity on six organs in each of the three stages. Among these findings, conspicuous and relevant ones will be considered.

The findings of the G-6-PD and TPND activity in the adrenal cortex of the $\mathrm{N}$ group are in accord with those of COHEN ${ }^{37}$. Unusually high levels of G-6-PD activity were found biochemically in adrenal cortical tissue by Kelly et $\mathrm{al}^{38)}$. The enzyme, G-6-PD in the adrenal cortex, as CoHen said, is considered to act as a reduced triphosphopyridine nucleotide (TPNH) generator. This TPNH is required as a cofactor for the hydroxylases which is important for steroid synthesis. Consequently, the elevation of the G-6-PD activity, especially in the middle and outer part of the zona fasciculata and reticularis from the pre-hypertensive stage, and in the glomerulosa after the incidence of hypertension seems to suggest the increase of steroid synthesis in each zone of the adrenal cortex of the SH rat from each corresponding stage. It is inferred, therefore, that the synthesis in the zona fasciculata and reticularis is promoted after the incidence of hypertension and becomes manifest in the advanced stage of hypertension. On the other hand, the augmented TPND activity in the adrenal cortex of the $\mathrm{SH}$ group from the pre-hypertensive stage in the zona fasciculata and reticularis, and after the incidence of hypertension in the glomerulosa, means also the rise of the oxidation of much of the TPNH via this enzyme in these zones in each stage. But the increasing degree of TPND activity is less than that of G-6-PD according to age. This finding should be thought of as an incidental change to the enhancement of the G-6-PD activity in each zone respectively. Glucocorticoids ${ }^{39)}$ are secreted from the fasciculata and hypertension can be induced experimentally by the administration of them ${ }^{40-44)}$. The hyperfunction of the zona fasciculata of the adrenal cortex in SH rats drawn from the histochemical findings concurs with the histologically determined hypertrophy of the zone ${ }^{9)}$. This hyperfunction can be considered as a cause of the development and maintenance of hypertension in this rat. The hyperfunction of the zona fasciculata might go with the histological findings in the anterior pituitary of $\mathrm{SH}$ rats that increase in the percentage ratio of basophils existed from the pre-hypertensive stage ${ }^{9}$.

On the other hand, it is generally believed that the zona glomerulosa is the site of aldosterone production ${ }^{39) 45)}$. In the glomerulosa of SH rats, rise of G-6-PD and TPND activity was observed histochemically after the development of hypertension, hypertrophy detected histologically and increase in its lipid content was detected also from the pre-hypertensive stage. From these findings, it should be inferred that hypersecretion of aldosterone in the $\mathrm{SH}$ group is likely to be present at least after the incidence of hypertension. Meanwhile, the zona glomerulosa appears to react demonstrably to alteration in electrolyte concentration ${ }^{46-48)}$. It is not clear, however, whether or not this is regulated by the increase in renin release or of angiotensin formation ${ }^{39) 47749-54)}$. At any rate, hyperfunction of the glomerulosa is considered to occur in the SH group at least after the incidence of hypertension and it is probable that hyperfunction of this zone plays a certain role in hypertensive condition.

SoBeL ${ }^{55) 56)}$ verified histologically, histochemically and biochemically that the ACPase activi- 
ty in the follicular cells of the rat thyroid showed rise when they received exposure to cold, and reduced when they got thyroxin treatment. This fact means the alteration in ACPase activity in the thyroid indicates the rate of thyroid hormone synthesis. Increase of ACPase activity in the follicular cells of the thyroid of $\mathrm{SH}$ rats through all stages is consistent with that of the cases exposed to cold by SoBEL ${ }^{55}{ }^{56)}$. The histological and histometrical findings on the thyroid of $\mathrm{SH}$ rats also suggest the increase of the function. Consequently, it seems to suggest that there exists an increase of secretory activity of the thyroid in $\mathrm{SH}$ rats from the pre-hypertensive stage becoming more marked after the incidence of hypertension as determined by both histological and histochemical studies. Moreover, the thyroid of $\mathrm{SH}$ rats gained manifestly in weight in the advanced stage of hypertension. Thyroxin increases cardiac output in cooperation with the effect of catecholamine so that pulse pressure and heart rate are increased ${ }^{57)}$. Patients with hyperthyroidism frequently display hypertension ${ }^{58)}$. When thyroid powder was administered to $\mathrm{SH}$ rats, the blood pressure rose much higher than that of normotensives ${ }^{11)}$. In addition, it has been confirmed in rats that thyroxin enhances hypertension due to corticosteroids ${ }^{59)}$. Consequently the hyperfunction of the thyroid in $\mathrm{SH}$ rats is also a factor for the occurrence and maintenance of hypertension attending on the adrenal cortical hyperactivity in this rat. The hyperfunction of the thyroid may correspond also to the increase of the percentage ratio of basophils in the anterior pituitary from the pre-hypertensive stage ${ }^{97}$.

It is suggested that the presence of ATPATPase system in the vascular walls is an indispensable prerequisite to the contraction of vascular smooth muscle and that a disturbance of this ATP-ATPase system in the blood vessels is important concerning the pathogenesis of hypertension ${ }^{60)}$. NAKAJIMA ${ }^{61)}$ did studies on ATPase in dog kidneys and revealed that all the fractions which possessed the ATPase activity caused a remarkable rise of blood pressure when injected into another dog intravenously. Motomura ${ }^{62)}$ revealed that "acid ATPase" activity in the serum is higher in the hypertensives than in the normotensives. In the meantime, NAKAMоTo ${ }^{63)}$ planned a histochemical method for the demonstration of acid ATPase with the incubation medium at $\mathrm{pH} 5.5$ and reported that the activity was demonstrated moderately to markedly in such renal vascular walls as arteries of medium caliber, vasa afferens and glomerular capillaries using this technique. Consequently, histochemical findings on ATPase activity in the renal vascular system in rats of both the $\mathrm{N}$ and $\mathrm{SH}$ groups might be considered to be analogous to that of acid ATPase activity, at least from the histochemically detected localization point of view. Based on this, it can be assumed that the renal interlobular artery in some cases of $\mathrm{SH}$ rats showed a tendency to gain in contraction even from the pre-hypertensive stage, and both the interlobular artery and vasa afferens contract more intensely in all cases than those of normotensives after the development of hypertension. This must be also a factor concerning the hypertensive state. From the histochemical findings on ATPase activity of the renal vessels of $\mathrm{SH}$ rats, the interlobular arteries might be more intimately related with the severity and duration of hypertension. It cannot be settled at present, however, whether these changes in renal vessels play some role as a cause of hypertension in $\mathrm{SH}$ rats or occur rather as an effect of it.

The pattern of distribution of noradrenalinstoring cell islets in the adrenal medulla of a rat, using the glutaraldehyde-osmium tetroxide technique is reported to correspond to that observed after the application of the iodate or fluorescent methods ${ }^{36) 64)}$. Two possible causes can be considered from the finding, observed in the adrenal medulla of $\mathrm{SH}$ rats with this technique, that the noradrenalin-storing cell islets of $\mathrm{SH}$ rats indicate a stronger reaction with about twice the mean dimensional ratio to the whole adrenal medulla than is found in normotensives through all stages. One is the increase of synthesis of noradrenalin in these reaction positive cells, the other is the increase of retention of noradrenalin because of the reduction of release. This latter is 
unaffected by the production rate of noradrenalin in these cells which is normal or below average. On the other hand, the noradrenalin content of the adrenals of SH rats was reported to show a slight increasing tendency in the hypertensive state (This was announced in only a brief excerpt ${ }^{65)}$ and in personal communication by OzAKI.). Further, according to the unpublished data of the Department of Pathology, Faculty of Medicine, Kyoto University, (Oкамото, Yamori and Suzuki), the noradrenalin content of adrenals of $\mathrm{SH}$ rats significantly indicated about double that of normotensives in the initial stage of hypertension. This evidence coincides with the above histochemical finding.

The adrenal medulla is mainly innervated by the sympathetic nervous system without effective counteraction of the parasympathetic system. If this histochemical finding depends on the former, the enhancement of the noradrenalin synthesis, it may be induced that overactivity of the sympathetic nervous system exists in $\mathrm{SH}$ rats from the pre-hypertensive stage and that the release of hormone also increases. Anyway, from this finding concerning the adrenal medulla of $\mathrm{SH}$ rats alone, it cannot be decided which interpretation is more probable.

Increase of MAO activity in the heart muscle of $\mathrm{SH}$ rats was detected after the development of hypertension with the histochemical technique after GLENNER ${ }^{25)}$, using tryptamine hydrochloride as substrate.

Though this finding may be partly due to the specific reaction to tryptamine as substrate, it seems to be mostly due to the presence of a real increase of MAO activity itself. NovICK ${ }^{66)}$ obtained a significant increase of MAO activity in the heart after administration of thyroid hormone. Consequently there is good evidence to assume that increase of cardiac MAO activity is partly caused by the thyroid hyperfunction in $\mathrm{SH}$ rats. CRout et al. ${ }^{67)}$ called MAO to account as the most relevant enzyme concerning the metabolism of endogenous noradrenalin in the heart of the rat. There is information to the effect that cardiac noradrenalin stores of $\mathrm{SH}$ rats tend to rise slightly after the development of hypertension (OzakI in a brief excerpt ${ }^{65)}$ and personal communication). Moreover, in SH rats, dominant cardiac hypertrophy was observed after the incidence of hypertension, so that the cardiac catecholamine stores and MAO activity also seem to be playing a greater part in the mechanism of hypertension. On the basis of these changes found in the adrenal medulla and heart muscle, it should be conceived that the catecholamine synthesis and metabolism, such as noradrenalin synthesis in the adrenal medulla, cardiac catecholamine stores and its metabolism, primarily the oxidative deamination, in the heart muscle of SH rats increase generally in the hypertensive condition and as a result of these, the mechanism terminating the biological response to catecholamine as an important role in the heart is obviously promoted after the development of hypertension in $\mathrm{SH}$ rats.

It has been observed that there are no significant changes in heart and adrenal catecholamine content in dogs with renal or neurogenic hypertension, both of which were examined 2-3 weeks after operation ${ }^{68)}$, or in rats with renal hypertension which were sacrificed 8-12 weeks after operation ${ }^{69)}$. Augmented cardiac adrenalin content has been reported in some cases of chronic condition of essential hypertension ${ }^{70)}$. There have been no reports, however, on a regular change in the cardiac MAO activity in hypertension. Considering this, the presence of marked elevation of MAO activity in the heart muscle of $\mathrm{SH}$ rats after the development of hypertension may be caused by superimposition of the factors that these animals survive with the higher extent and the longer duration of hypertension, and that they may show some characteristic reaction in the heart.

The urinary excretion of catecholamine was not significantly changed in chronic renal hypertensive dogs, $3-8$ weeks after operation ${ }^{71}$. Although patients with essential hypertension have been reported to excrete slightly elevated ${ }^{78-77)}$, normal ${ }^{76), 78-85)}$, and reduced ${ }^{84)}$ amounts of noradrenalin and its metabolites in their urine, there is little doubt that the majority of them excreted no more than normal quantities. As generally noted, few positive results have been reported concerning the role of 
catecholamine in experimental and essential hypertension from such points of view as, for instance, the content in organs or volume of excretion. On the other hand, in spite of reports that significant increase of catecholamine has seldom been recognized in hypertension, especially in the essential type, most kinds of antihypertensive drugs are substances which act to tranquilize the autonomic nervous system, to inhibit the secretion or the synthesis of catecholamine or to promote the release of it.

Considering this, changes detected in noradrenalin reaction of the adrenal medulla and in MAO activity of the heart muscle of SH rats seem possibly to perform some significant role concerning the development and maintenance of hypertension in these animals. Furthermore, from this standpoint, increase of the mean dimensional ratio of noradrenalinstoring cell islets in the adrenal medulla of SH rats might have another important meaning as an indicator of the existence of the sympathetic overactivity in these animals.

Enhancement of vascular reactivity to noradrenalin has become known in experimental and essential hypertension ${ }^{85) 86)}$. Moreover, thyroxin and glucocorticoids potentiate the effects of catecholamine, primarily noradrenalin to the vascular wall ${ }^{87) 88)}$. RAAB ${ }^{89)}$ suggested that the reactivity of the vascular wall was augmented by the increase of the sodium amount in it and such vessels became more sensitive to aldosterone or angiotensin. These elements may be also responsible for the mechanism of hypertension in $\mathrm{SH}$ rats.

From the evidence that the histochemical changes in the adrenal cortex and medulla, and thyroid and histological findings in the anterior pituitary ${ }^{9)}$ were observed in $\mathrm{SH}$ rats from the pre-hypertensive stage and that these findings showed an increasing tendency according to age, the following presumption seems to be applicable : Namely, in SH rats, from the prehypertensive stage, hyperfunction of the adenohypophyseo-adrenocortical axis, the adenohypophyseo-thyroid system and, in addition, possible overactivity of the system of sympathetic nerve-adrenal medulla exist coincidentally. These organized changes may play the principal part in producing hypertension in $\mathrm{SH}$ rats.

\section{Summary}

Spontaneously hypertensive rats (Oкамото and Aokr) were sacrificed in the pre-hypertensive stage (40 to 60 days after birth), initial stage ( 5 to 7 months after birth) or advanced stage of hypertension (13 to 17 months after birth). Twenty-one kinds of enzyme activity were examined histochemically in the adrenals, thyroid, kidneys, heart, liver and pancreas, and noradrenalin reaction was also applied to the adrenal medulla. Each positive finding in spontaneously hypertensive rats was obtained by comparing it with the reaction of the same sex normotensive Wistar strain rats with almost the same survival duration.

1) Glucose-6-phosphate dehydrogenase and triphosphopyridine nucleotide diaphorase activity increased in the zona fasciculata and reticularis of the adrenal cortex of spontaneously hypertensive rats with dominant elevation of the former activity in the middle and outer part of the fascicular zone from the pre-hypertensive stage. More prominent increase was observed after the incidence of hypertension.

2) The noradrenalin-storing cell islets in the adrenal medulla of spontaneously hypertensive rats indicated a stronger reaction with about twice the mean dimensional ratio to the whole adrenal medulla in all stages than was found in normotensives.

3) Acid phosphatase activity in the follicular cells of the thyroid in spontaneously hypertensive rats was elevated from the pre-hypertensive stage.

4) Adenosine triphosphatase activity of the renal interlobular arteries of spontaneously hypertensive rats showed an increase in about half the cases in the pre-hypertensive stage and in all cases after the incidence of hypertension.

5) Glucose-6-phosphate dehydrogenase and triphophopyridine nucleotide diaphorase activity in the zona glomerulosa of the adrenal cortex of spontaneously hypertensive rats rose after the incidence of hypertension, though 
the latter activity showed only a slightly increasing tendency.

6) Increase of adenosine triphosphatase activity in the walls of renal interlobular arteries and vasa afferens of spontaneously hypertensive rats was detected in all cases after the incidence of hypertension.

7) Gradual elevation of monoamine oxidase activity in the heart muscle of spontaneously hypertensive rats occurred after the incidence of hypertension.

8) No constant difference was found in the results of other kinds of enzyme histochemical comparisons of adrenals, thyroid, kidneys or heart, or in the enzyme histochemistry of the liver or pancreas, either.

9) From the above-mentioned evidence, it may be assumed that there exists from the pre-hypertensive stage in spontaneously hypertensive rats, an increase of (1) glucocorticoids synthesis in the adrenal cortex; (2) either synthesis of noradrenalin, or retention of it in the adrenal medulla; (3) secretory activity of the thyroid and (4) the contracting tendency of the renal vessels of medium caliber. In addition, after the incidence of hypertension, elevation of (5) aldosterone synthesis in the zona glomerulosa of the adrenal cortex; (6) the contraction of the renal vessels and (7) the catecholamine metabolism, primarily the oxidative deamination in the heart muscle is also indicated.

\section{Acknowledgement}

The author wishes to express his grateful appreciation to the following fellow researchers in this laboratory: Dr. Toshio Takeda for his invaluable advice, Dr. Tsuneyuki Suzuki for collaboration in staining procedure, Dr. Masakazu Fukushima for assisting in the care and examination of specimens and Drs. Shoichiro Nosaka and Yukio Yamori for their useful suggestions, and to Mr. Kanji Tsuchida for technical assistance.

\section{REFERENCES}

1) Okamoto, K. and Aoki, K., Development of a strain of spontaneously hypertensive rats. Jap. Circul. J. 27: 282-293, 1963,

2) Smirk, F. H. and Hall, W. H., Inherited hypertension in rats. Nature $\mathbf{1 8 2}: 727-728,1958$.

3) Laverty, R. and Smirk, F. H., Observations on the pathogenesis of spontaneous inherited hypertension and constricted renal-artery hypertension in rats. Circulat. Res. $9: 455-464,1961$.

4) Phelan, E. L., Eryetisher, I. and Smirk, F. H., Ob- servations on the responses of rats with spontaneous hypertension and control rats to pressor drugs and to hexamethonium. Circulat. Res. 10:817-824, 1962.

5) Alexander, N., Hinshaw, L. B. and Drury, D. R., Development of a strain of spontaneously hypertensive rabbits. Proc. Soc. Exp. Biol. Med.86:855858, 1954.

6) Alexander, N., Hinshaw, L. B. and Drury, D. R., Further observations on development of a colony of spontaneously hypertensive rabbits. Proc. Soc. Exp. Biol. Med. 92 : 249-253, 1956.

7) Okamoto, K., Aoki, K., Nosaka, S. and Fukushima, M., Cardiovascular diseases in the spontaneously hypertensive rat. Jap. Circul.J. 28 : 943-952, 1964.

8) Okamoto, K., Experimental studies on the relationship between endocrine organs and hypertension. Folia Endocrinol. Jap. 38 : 782-794, 1962 (in Japanese).

9) Aoki, K., Tankawa, H., Fujinami, T., Miyazaki, A. and Hashimoto, Y., Pathological studies on the endocrine organs of the spontaneously hypertensive rats. Jap. Heart J. 4:426-442, 1963.

10) Aoki, K., Experimental studies on the relationship between endocrine organs and hypertension in spontaneously hypertensive rats; I. Effects of hypophysectomy, adrenalectomy, thyroidectomy, nephrectomy and sympathectomy on blood pressure. Jap. Heart J. 4: 443-461, 1963.

11) Aoki, K., Experimental studies on the relationship between endocrine organs and hypertension in spontaneously hypertensive rats; II. Effects of various hormones on blood pressure. Jap. Heart J. 4: 561-576, 1963.

12) Aoki, K., Experimental studies on the relationship between endocrine organs and hypertension in spontaneously hypertensive rats; III. Role of the endocrine organs and hormones. Jap. Heart J. 5 : 57-68, 1964.

13) Okamoto, K., Tabei, R., Fukushima, M., Nosaka, S., Yamori, Y., Ichijima, K., Haebara, H., Matsumoto, M., Maruyama, T., Suzuki, Y. and Tamegai, M., Further observations on the development of a strain of spontaneously hypertensive rats. $J a p$. Circul. J. 30: 703-716, 1966.

14) Burstone, M. S., Histochemical comparisons of Naphthol AS-phosphates for the demonstration of phosphatases. J. Nat. Cancer Inst. 20: 601-615, 1958.

15) Burstone, M.S., The relationship between fixation and techniques for the histochemical localization of hydrolytic enzymes. "Symposium." J. Histochem. Cytochem. 6:322-339, 1958.

16) Burstone, M. S., Histochemical demonstration of phosphatases in frozen sections with Naphthol ASphosphates. J. Histochem. Cytochem. 9: 146-153, 1961.

17) Gomori, G., An improved histochemical technic for acid phosphatase. Stain Technol. 25: 81-85, 1950.

18) Gomori, G., Microscopic Histochemistry; Principles and practise. Systematic histochemistry, enzymes, hydrolytic enzymes, acid phosphatase, 189-194, Univ. Chicago Press, Chicago, Illinois, 1952. 
19) Wachstein, M. and Meisel, E., Histochemistry of hepatic phosphatases at a physiological $\mathrm{pH}$ with special reference to the demonstration of bile canaliculi. Am. J. Clin. Pathol. 27 : 13-23, 1957.

20) Wachstein, M. and Meisel, E., On the histochemical demonstration of glucose-6-phosphatase. $J$. Histochem. Cytochem. $4: 592,1956$.

21) Wachstein, M. and Meisel, E., A comparative study of enzymatic staining reactions in the rat kidney with necrobiosis induced by ischemia and nephrotoxic agents (mercuhydrin and DL-serine). $J$. Histochem. Cytochem. 5 : 204-220, 1957.

22) Burstone, M. S., Esterase activity of developing bones and teeth. Arch. Path., 63 : 164-167, 1957.

23) Burstone, M. S., The relationship between fixation and techniques for the histochemical localization of hydrolytic enzymes. J. Histochem. Cytochem. 6 : 322-339, 1958.

24) Gomori, G., Microscopic Histochemistry; Principles and practice. Systematic histochemistry, enzymes, hydrolytic enzymes, esterases, 200-215, Univ. Chicago Press, Chicago, Illinois, 1952.

25) Glenner, G. G., Burtner, H. J. and Brown, G. W. Jr., The histochemical demonstration of monoamine oxidase activity by tetrazolium salts. J. Histochem. Cytochem. 5: 591-600, 1957.

26) Burstone, M. S., New histochemical techniques for the demonstration of tissue oxidase. J. Histochem Cytochem. 7 : 112-122, 1959.

27) Burstone, M.S., Enzyme histochemistry and its application in the study of neoplasms; Dehydrogenases, histochemical methods, 515, Academic Press, New York and London, 1962.

28) Nachlas, M. M., Tsou, K. C., Souza, E. De., Chang, C. S. and Seligman, A. M., Cytochemical demonstration of succinic dehydrogenase by the use of a new p-nitrophenyl substituted ditetrazole. 5 : 420436, 1957.

29) Hess, R., Scarpelli, D.G. and Pearse, A. G. E., Cytochemical localization of pyridine nucleotide-linked dehydrogenases. Nature 181 : 1531-1532, 1958.

30) Levy, H., Deane, H. W. and Rubin, B. L., Visualization of steroid-3 $\beta$-ol-dehydrogenase activity in tissues of intact and hypophysectomized rats. Endocrinol. 65 : 932-943, 1959.

31) Seligman, A. M., Tsou, K-C., Rutenburg, S. H. and Cohen, R. B., Histochemical demonstration of $\beta$-Dglucuronidase with a synthetic substrate. J. Histochem. Cytochem. 2: 209-229, 1954.

32) Nachlas, M. M., Crawford, D. T. and Seligman, A. M., The histochemical demonstration of leucine aminopeptidase. J. Histochem. Cytochem. 5: 264278, 1957.

33) Okamoto, K., Ueda, M., Maeda, R. and Mizutani, A., Microscopic histochemistry; Histochemical methods for organic compounds, enzymes, acid phosphatase, 522-523, Igaku Shoin Ltd., Tokyo \& Osaka, 1965 (in Japanese).

34) Pearse, A. G.E., Histochemistry, theoretical and applied, carboxylic esterases, methods for lipases, 475, J. \& A. Churchill, Ltd., London, 1961.

35) Takamatsu, H., Ohkawa, K., Kumazawa, K. and Nagai, T., Histochemical studies on the lipases and esterases, with special reference to new methods for the histochemical demonstration and to the substrate specificity of these enzymes. Acta Tubercul. Jap. 11: 98-110, 1963 (in Japanese).

36) Coupland, R. E., Pyper, A. S. and Hopwood, D., A method for differentiating between noradrenalineand adrenaline-storing cells in the light and electron microscope. Nature 201 : 1240-1242, 1964.

37) Cohen, R. B., Histochemical localization and metabolic significance of glucose-6-phosphate dehydrogenase system in adrenal cortex. Proc. Soc. Exp. Biol. Med. 101 : 405-407, 1959.

38) Kelly, T. L., Nielson, E. D., Johnson, R. B. and Vestling, C. S., Glucose-6-phosphate dehydrogenase of adrenal tissue. J. Biol. Chem. 545-554, 1955.

39) Stachenko, J. and Giroud, C. J. P., Functional zonation of the adrenal cortex; Pathways of corticosteroid biogenesis. Endocrinol. 64 : 730-742, 1959.

40) Knowlton, A. I., Loeb, E. N., Stoerk, H. C., White J.P. and Hefferman, J. F., Induction of arterial hypertension in normal and adrenalectomized rats given cortisone acetate. J. Exp. Med. 96: 187-205, 1952.

41) Friedman, S. M., Friedman, C. L. and Nakashima, M., Further observations on the hypertensive properties of compound F acetate in the rat. Endocrinol. 53 : 633-639, 1953.

42) Knowlton, A. I., Loeb, E. N. and Stoerk, H. C., Effect of synthetic analogous of hydrocortisone on the blood pressure of adrenalectomized rats on sodium restriction. Endocrinol. 60: 768-777, 1957.

43) Skelton, F. R., Production and inhibition of hypertension disease in the rat by corticosterone. Endocrinol. 62:365-368, 1958.

44) Gross, F., Essential hypertension ; An international symposium. Adrenocortical function and renal pressor mechanism in experimental hypertension. 92-111, Springer-Varlag, Berlin-Goettingen-Heidelberg, 1960.

45) Hartroft, W.S. and Hartroft, P.M. ,New approaches in the study of cardiovascular disease ; aldosterone, renin, hypertension and juxtaglomerular cells. Fed. Proc. $20: 845-854,1961$.

46) Hartroft, P. M. and Hartroft, W.S., Studies on renal juxtaglomerular cells ; II. Correlation of the degree of granulation of juxtaglomerular cells with width of the zona glomerulosa of the adrenal cortex. J. Exp. Med. 102: 205-212, 1955.

47) Cohen, R. B. and Crawford, J. D., Distribution of glycogen, lipid and glucose-6-phosphate dehydrogenase activity in the adrenal cortex of the sodium depleted rat; a histochemical study. Endocrinol. $71: 847-852,1962$.

48) Marx, A. J. and Deane, H. W., Histophysiological changes in the kidney and adrenal cortex in rats on a low-sodium diet. Endocrinol. 73: 317-328, 1963.

49) Edelman, R. and Hartroft, P. M., Localization of renin in juxtaglomerular cells of rabbit and dog through the use of the fluorescent-andibody technique. Circulat. Res. 9: 1069-1077, 1961.

50) Bing, J. and Kazimierczak, J., Renin content of different parts of the juxtaglomerular apparatus; 4. Localization of renin in the kidney. Acta path. microbiol. Scand. 54 : 80-84, 1962. 
51) Page, I. H., Essential hypertension; An international symposium. The mosaic theory of hypertension. 1-29, Springer-Verlag, Berlin-GoettingenHeidelberg, 1960.

52) Deane, H. W. and Masson, G. M. C., Adrenal cortical changes in rats with various types of experimental hypertension. J. Clin. Endocrinol. 11:193208, 1951.

53) Laragh, J. H., Angers, M., Kelly, W. G. and Lieberman, S., Hypotensive agents and pressor substances; The effect of epinephrine, norepinephrine, angiotensin II, and others on the secretory rate of aldosterone in man. J. A. M. A. $174: 234-240,1960$.

54) Ames, R. P., Borkowski, A. J., Sicinski, A. M. and Laragh, J. H., Prolonged infusions of angiotensin II and norepinephrine and blood pressure, electrolyte balance, and aldosterone and cortisol secretion in normal man and in cirrhosis with ascites. $J$. Clin. Invest. 44 : 1171-1186, 1965.

55) Sobel, H. J., The localization of acid phosphatase activity in the rat pituitary and thyroid glands and its relation to secretory activity. Endocrinol. 68: 801-808, 1961.

56) Sobel, H. J., Phosphatases of rat thyroid and anterior pituitary glands during various phases of secretory activity; A cytochemical study. J. Endocrinol. 30 : 323-336, 1964.

57) Ganong, W. F., Review of medical physiology; The thyroid gland, 228-244, Lange Medical Publications, Maruzen Co., Ltd., (Asian Edition), 1963.

58) Williams, R.H. and Bakke, J. L., The thyroid: Diseases of the thyroid, manifestations of Graves' disease, 154-169, from Textbook of Endocrinology, edited by Williams, R. H., Saunders Co., Philadelphia and London, 1962.

59) Masson, G. M. C., Corcoran, A. C. and Page, I. H., Effects of renin and thyroxine in rats treated with corticosteroids and in rats with regenerating adrenals. Endocrinol. 61 : 409-418, 1957.

60) Maekawa, M., Hypertension (Its causal aspects); The hyperactivity of the ATP-ATPase system, especially the mobilization of the kidney ATPase as the direct cause of hypertension in general. Jap. Circul. J. 17: 153-210, 1953.

61) Nakajima, O., Studies on ATPases of kidney (1); Semipurification of the soluble ATPase of kidney. Jap. Circul. J. 21 : 1-7, 1958.

62) Motomura, S., Studies on the dephosphorylation of adenosine-triphosphate by human sera with emphasis on hypertensive sera. Acta Scholae Med. Univ. Kioto 35 : 190-212, 1958.

63) Nakamoto, K., Histochemical studies on phosphatases and ATPases with special reference to acid ATPase. Acta Scholae Med. Univ. Kioto 37 : 414-445, 1961.

64) Tramezzani, J. H., Chiocchio, S. and Wassermann, G. F., A technique for light and electron microscopic identification of adrenalin- and noradrenalinstoring cells. J. Histochem. Cytochem. 12: 890-899, 1964.

65) Ozaki, M., Symposium on the biochemistry of indole derivatives; Metabolism of serotonin in spontaneously hypertensive rats. J. Jap. Biochem. Soc. $36:$ 506, 1964 (in Japanese).
66) Novick, W. J., The effect of age and thyroid hormones on the monoamine oxidase of rat heart. Endocrinol. 69 : 55-59, 1961.

67) Crout, J. R., Creveling, C. R. and Udenfriend, S., Norepinephrine metabolism in rat brain and heart., J. Pharmacol. Exp. Ther. 132 : 269-277, 1961.

68) Wegmann, A., Kako, K. and Bing, R. J., Catecholamine content of various organs in experimental hypertension. Am. J. Physiol. 203 : 607-608, 1962.

69) De Schaepdryver, A.F., Taquini, A.C. Jr., Bernard, P. and Heymans, C., Tissue catecholamines in chronic renal hypertension. Arch. Int. Pharmacodyn. 142 : 260-266, 1963 .

70) Raab, W. and Gigee, A.B., Norepinephrine and epinephrine content of normal and diseased human hearts. Circulation, 11 : 593-603, 1955.

71) Masuyama, Y., Yamanaka, Y., Ohno, Y., Inoue, N., Sugiyama, K., Murata, T. and Suzuki, H., The role of neural factors in experimental renal hypertension. Jap. Heart J. 2 : 505-523, 1961.

72) Holtz, P., Credner, K. and Kronenberg, G., Ueber das Sympathicomimetische Pressorische Prinzip des Harns (,Urosympathin"). Arch. Exp. Path. Pharmakol. 204 ; 228-243, 1947.

73) von Euler, U.S., Some aspects of the clinical physiology of noradrenaline. Scandinav. J. Clin. Lab. Invest. $4: 254,1952$. (Cited by Gitlow, S. E., Mendlowitz, M., Smith, A., Gall, E., Wolf, R. L. and Naftchi, N. E., Pharmacology and metabolism of norepinephrine in patients with essential hypertension. Am. J. Cardiol. 9: 717-723, 1962.)

74) von Euler, U. S., Heilner, S. and Purkhold, A., Excretion of noradrenaline in urine in hypertension. Scandinav. J. Clin. Lab. Invest. 6: 54, 1954. (Cited by Gitlow, S. E., Mendlowitz, M., Smith, A., Gall, E., Wolf, R. L. and Naftchi, N. E., Pharmacology and metabolism of norepinephrine in patients with essential hypertension. Am. J. Cardiol. 9: 717-723, 1962.)

75) Goldenberg, M., Serlin, I., Edwards, T. and Rapport, M.M., Chemical screening methods for the diagnosis of pheochromocytoma ; I. Norepinephrine and epinephrine in human urine. Am. J. Med. 16:310-327, 1954.

76) von Euler, U. S., Noradrenaline; Chemistry, physiology, pharmacology and clinical aspects. Excretion in urine, 285-302, Charles C. Thomas Publisher, Springfield, Illinois, 1956.

77) Goodall, Mc C. and Bogdonoff, M., Essential hypertension with an elevated noradrenaline excretion. Am. Heart J. 61 : 640-645, 1961.

78) Birke, G., Dunér, H., von Euler, U. S. and Plantin, L. O., Studies on the adrenocortical, adreno-medullary and adrenergic nerve activity in essential hypertension. Ztschr. Vitamin-, Hormon-, Fermentforsh. 9: 41-68, 1957.

79) Griffiths, W. J. and Collinson, S., The estimation of noradrenaline in urine and its excretion in normal and hypertensive subjects. J. Clin. Path. 10:120, 1957. (Cited by Gitlow, S. E., Mendlowitz, M., Smith, A., Gall, E., Wolf, R. L. and Naftchi, N. E., Pharmacology and metabolism of norepinephrine in patients with essential hypertension. $A m$. J. Cardiol. 9 : 717-723, 1962.) 
80) Gitlow, S. E., Mendlowitz, M. Khassis, S., Cohen, G. and Sha, J., The diagnosis of pheochromocytoma by determination of urinary 3-methoxy, 4-hydroxymandelic acid. J. Clin. Invest. 39 : 221-226, 1960.

81) Crout, J.R., Pisano, J.J. and Sjoerdsma, A., Urinary excretion of catecholamines and their metabolites in pheochromocytoma. Am.Heart J. 61: 375-381, 1961.

82) Sato, T., Yoshinaga, K., Wada, Y., Ishida, N. and Itoh, C., Urinary excretion of catecholamines and their metabolites in normotensive and hypertensive subjects. Tohoku J. Exp. Med. 75: 151-157, 1961.

83) Mikami, M., Koyama, C., Araki, N., Akutsu, H., Kobayashi, S., Sugano, T., Muto, M. and Hashimoto, M., Clinical study on essential hypertension; The relationship between pharmacological test and excretion of urinary catecholamine on juvenile essential hypertension. J. Jap. Soc. Int. Med. 52: 1169-1175, 1964.

84) Moeller, P., Buus, O. and Bierring, E., Blood pres- sure and urinary excretion of noradrenaline. Scandinav. J. Clin. Lab. Invest. 9: 331-337, 1957.

85) Swan, H. J. C., Noradrenaline, adrenaline and the human circulation. Brit. Med.J. 1 : 1003-1006, 1952.

86) Mendlowitz, M., Gitlow, S. and Naftchi, N., The cause of essential hypertension. Perspect. Biol. Med. 2: 354-361, 1959.

87) Brewster, W. R., Isaacs, J. P., Osgood, P. F. and King, T. L., The hemodynamic and metabolic interrelationships in the activity of epinephrine, norepinephrine and the thyroid hormones. Circulation 13 : 1-20, 1956.

88) Mendlowitz, M., Gitlow, S. and Naftchi, N., Work of digital vasoconstriction produced by infused norepinephrine in Cushing's syndrome. J. Appl. Physiol. 13 : 252-256, 1958.

89) Raab, W., Hypertension, recent advances; Etiologic role of catecholamines in essential hypertension, 369-378, Lea \& Febiger, Philadelphia, 1961. 